\title{
A Novel Injectable Magnesium/Calcium Sulfate Hemihydrate Composite Cement for Bone Regeneration
}

\author{
Shanchuan Zhang, ${ }^{1,2}$ Ke Yang, ${ }^{3}$ Fuzhai Cui, ${ }^{4}$ Yi Jiang, ${ }^{5}$ Lingling E, \\ Baohua $\mathrm{Xu},{ }^{1}$ and Hongchen Liu ${ }^{2}$ \\ ${ }^{1}$ Center of Stomatology, China-Japan Friendship Hospital, Beijing 100029, China \\ ${ }^{2}$ Institute of Stomatology, General Hospital of Chinese PLA, Beijing 100853, China \\ ${ }^{3}$ Specialized Materials and Devices Division, Institute of Metal Research, Chinese Academy of Sciences, Shenyang 110016, China \\ ${ }^{4}$ Advanced Materials Laboratory, Tsinghua University, Beijing 100084, China \\ ${ }^{5}$ Department of Geriatric Dentistry, General Hospital of Chinese PLA, Beijing 100853, China
}

Correspondence should be addressed to Baohua Xu; baohuaxuu@163.com and Hongchen Liu; hongchenldr@163.com

Received 7 January 2015; Accepted 18 March 2015

Academic Editor: Ali I. Abdalla

Copyright (C) 2015 Shanchuan Zhang et al. This is an open access article distributed under the Creative Commons Attribution License, which permits unrestricted use, distribution, and reproduction in any medium, provided the original work is properly cited.

Objective. A novel injectable magnesium/calcium sulfate hemihydrate $(\mathrm{Mg} / \mathrm{CSH})$ composite with improved properties was reported here. Methods. Composition, setting time, injectability, compressive strength, and bioactivity in simulated body fluid (SBF) of the $\mathrm{Mg} / \mathrm{CSH}$ composite were evaluated. Furthermore, the cellular responses of canine bone marrow stromal cells (cBMSCs) and bone formation capacity after the implantation of $\mathrm{Mg} / \mathrm{CSH}$ in tibia defects of canine were investigated. Results. $\mathrm{Mg} / \mathrm{CSH}$ possessed a prolonged setting time and markedly improved injectability and mechanical property $(p<0.05) . \mathrm{Mg} / \mathrm{CSH}$ samples showed better degradability than CSH in SBF after 21 days of soaking $(p<0.05)$. Moreover, the degrees of cell attachment, proliferation, and capability of osteogenic differentiation on the $\mathrm{Mg} / \mathrm{CSH}$ specimens were higher than those on $\mathrm{CSH}$, without significant cytotoxicity and with the increased proliferation index, ALP activity, and expression levels of integrin $\beta 1$ and Coll I in cBMSCs $(p<0.05)$. $\mathrm{Mg} / \mathrm{CSH}$ enhanced the efficiency of new bone formation at the tibia defect area, including the significantly elevated bone mineral density, bone area fraction, and Coll I expression level $(p<0.05)$. Conclusions. The results implied that this new injectable bone scaffold exhibited promising prospects for bone repair and had a great potential in bone tissue engineering.

\section{Introduction}

Bone defects are usually caused by trauma and nonunion, and autologous bone graft is commonly known as a gold standard in reconstruction of bone defects [1]. In the USA alone, approximately 1.6 million bone graft operations are performed for the treatment of bone defects every year [2]. However, the clinical use of autologous bone graft is accompanied by size limitations and a considerable donor site morbidity, like bleeding, hematoma, infection, and chronic pain. Currently, a variety of biomaterials, like acrylate-, calcium phosphate-, or apatite-based bone cements, and porous composites, are being used for reconstruction of bone defects [3].

Reportedly, calcium sulfate hemihydrate $\left(\mathrm{CaSO}_{4} \cdot 1 / 2 \mathrm{H}_{2} \mathrm{O}\right.$; $\mathrm{CSH}$ ) has long been used in clinic as a bone regeneration material, because it is characterized by low curing temperature (about $30^{\circ} \mathrm{C}$ ), rapid setting, excellent biocompatibility without inducing an inflammatory response, and promotion of bone healing [4-8]. However, the currently prepared CSH cement still has some limitations, which significantly limit its clinical applications. The solidified CSH paste has poor mechanical properties, which fails to provide constant longterm mechanical support for the defect site $[9,10]$. Poor bioactivity of $\mathrm{CSH}$ cement inhibits it from forming a chemical bond with bone tissue at the early stage of therapy $[8,11]$. Moreover, the fast resorption of CSH cement may negatively affect the bone regeneration $[12,13]$.

Among the various biodegradable materials, magnesium $(\mathrm{Mg})$ and its alloys have been utilized as metallic materials for medical implants because of their unique biocompatibility, 
nontoxicity, density, and elastic modulus similar to those of human bone and stimulatory effects on new bone formation [14-18]. However, in the physiological environment, they are corroded rapidly and thus lose the mechanical properties [19]. In order to lower the biodegradation ratio of Mg alloys, approaches like alkali-heat treatment [18], fluoride conversion coating [20], and plasma immersion ion implantation have been studied [21]. However, biocompatibility should be considered when graft material is used in human body. Considering the advantages and disadvantages of $\mathrm{CSH}$ and $\mathrm{Mg}$ alloys, it is proposed that the addition of $\mathrm{Mg}$ into $\mathrm{CSH}$ might result in a composite cement with improved properties and the $\mathrm{Mg} / \mathrm{CSH}$ composite scaffold could be used to repair bone defects.

In the present study, a composite cement was prepared by adding $\mathrm{Mg}$ into $\mathrm{CSH}$; meanwhile the setting time, injectability, mechanical properties, in vitro bioactivity, and biocompatibility with canine bone marrow stromal cells (cBMSCs) were evaluated. Moreover, in vivo bone formation capacity was also investigated by implanting the $\mathrm{Mg} / \mathrm{CSH}$ scaffold into a canine tibia defect model. It was expected that the novel $\mathrm{Mg} / \mathrm{CSH}$ composite cement could be potentially used for the clinical repair of bone defects.

\section{Materials and Methods}

2.1. Sample Preparation and Characterization. Mg powders were primarily prepared by a fluoride coating and micro-arc oxidation treatment (treated by Institute of Metal Research, Chinese Academy of Sciences, Shenyang, China). The $\mathrm{Mg} / \mathrm{CSH}$ powder was prepared by adding $\mathrm{Mg}$ powders (weight ratio: $0 \%, 10 \%$, and 20\%) into the $\mathrm{CSH}$ powder (purchased from Allgens Co., Ltd., China). Then, deionized water was added with a liquid to powder ratio of $0.6 \mathrm{~mL} / \mathrm{g}$ to moisten these powders. The mixtures were stirred within $60 \mathrm{~s}$ to form homogeneous pastes, transferred into Teflon molds $\left(\Phi 10 \mathrm{~mm} \times 20 \mathrm{~mm}\right.$ ) and then stored at $37^{\circ} \mathrm{C}$ for $24 \mathrm{~h}$; finally the hardened $10 \% \mathrm{Mg} / \mathrm{CSH}$ composite, $20 \% \mathrm{Mg} / \mathrm{CSH}$ composite, and pure CSH cements were obtained. The phase compositions of these samples were characterized by using X-ray diffraction (XRD; D8 Advance, Bruker (Beijing) Technology Co., Ltd., China) based on monochromated $\mathrm{CuK}_{\alpha}$ radiation $(\lambda=1.5405 \AA, 120 \mathrm{~mA}, 40 \mathrm{kV})$ in a continuous scan mode. The $2 \theta$ range was from $10^{\circ}$ to $90^{\circ}$ at a scanning speed of $8^{\circ} / \mathrm{min}$.

2.2. Setting Time, Injectability, and Compressive Strength. The setting time of $\mathrm{CSH}$ and $\mathrm{Mg} / \mathrm{CSH}$ composite pastes was measured with a Vicat needle (LeiYun Experimental Apparatus Manufacturing Co., Ltd., Shanghai, China) according to ISO9597-1989E. The initial setting time was defined as the time necessary for the light needle $(228.6 \mathrm{~g}, \varnothing 5.067 \mathrm{~mm})$ to plunge into the paste no longer leaving a visible print on the surface of the paste, while the final setting time was defined as the time necessary for the heavy needle $(306 \mathrm{~g}, \varnothing 1.140 \mathrm{~mm}$ ) to no longer leave a visible print on the surface of the paste. Five replicates were conducted for each group and the average value was calculated.

The injectability of $\mathrm{CSH}$ and composite pastes was tested by extruding a certain amount of paste through a $10 \mathrm{~mL}$ syringe with an opening nozzle (diameter: $2.8 \mathrm{~mm}$ ), according to a method described previously [22]. Those pastes were filled into syringe, and the syringe was gently pressed at a speed of $15 \mathrm{~mm} / \mathrm{min}$ until either pastes were completely extruded, or a maximum force of $100 \mathrm{~N}$ was reached. Then the weight of the extruded pastes was measured and the injectability was calculated by using the following formula: Injectability $(\%)=($ Weight of extruded paste/Weight of total paste initially contained in syringe) $\times 100 \%$.

Furthermore, the compressive strength of the hardened $\mathrm{CSH}$ and $\mathrm{Mg} / \mathrm{CSH}$ composite samples $(10 \mathrm{~mm}$ diameter $\times$ $20 \mathrm{~mm}$ high) was measured at a loading rate of $0.5 \mathrm{~mm} / \mathrm{min}$ with a universal testing machine (ZWICK Co. Ltd., Germany) in a way similar to that described in ASTM D695-91. The measurements were performed five times for each group.

2.3. In Vitro Immersion Test in Simulated Body Fluid (SBF). According to the method described by Kokubo [23], SBF was prepared, in which the degradation and bioactivity of $\mathrm{CSH}$ and $\mathrm{Mg} / \mathrm{CSH}$ composite cements were evaluated. SBF consisted of $142.0 \mathrm{mM} \mathrm{Na}^{+}, 5.0 \mathrm{mM} \mathrm{K}^{+}, 1.5 \mathrm{mM} \mathrm{Mg}^{2+}$, $2.5 \mathrm{mM} \mathrm{Ca}^{2+}, 148.8 \mathrm{mM} \mathrm{Cl}^{-}, 4.2 \mathrm{mM} \mathrm{HCO}_{3}{ }^{-}$, and $1.0 \mathrm{mM}$ $\mathrm{HPO}_{4}{ }^{2-}$ and was buffered at $\mathrm{pH} 7.25$ with $45 \mathrm{mM}$ hydrochloric acid $(\mathrm{HCl})$ and $50 \mathrm{mM}$ trishydroxymethyl aminoethane $\left(\left(\mathrm{CH}_{2} \mathrm{OH}\right)_{3}\left(\mathrm{CNH}_{2}\right)\right)$. After setting for $24 \mathrm{~h}$, the hardened $\mathrm{CSH}$ and $\mathrm{Mg} / \mathrm{CSH}$ composite specimens were immersed in $\mathrm{SBF}$ with a surface-area-to-volume ratio of $0.1 \mathrm{~cm}^{2} / \mathrm{cm}^{3}$ at $37^{\circ} \mathrm{C}$ for 21 days. The temperature of SBF was maintained by using a shaking water bath, and SBF was completely refreshed every day. For each group, five samples were removed from SBF after incubation for 2, 4, 7, 10, 14, and 21 days, respectively. At each time point, the specimens were gently rinsed with deionized water, dried in a $37^{\circ} \mathrm{C}$ oven for $24 \mathrm{~h}$, and then weighed. To measure in vitro degradation, weight loss percentage was calculated by using the following formula: Degradation ratio $=\left(W_{0}-W_{t}\right) / W_{0} \times 100 \%$, where $W_{t}$ and $W_{0}$ represent the dry weights of the degraded specimen and the initial specimen, respectively.

Furthermore, in order to evaluate the in vitro bioactivity of samples, scanning electron microscopy (SEM) equipped with an energy dispersive X-ray detector (EDX; Tescan Ltd., Shanghai, China) was utilized. Additionally, the $\mathrm{pH}$ values of SBF were measured during the test using an electrolyte-type $\mathrm{pH}$ meter.

2.4. Cell Culture and Osteogenic Induction. After intravenous anesthesia with $5 \%$ sodium pentobarbital $(0.5 \mathrm{~mL} / \mathrm{kg}), 5 \mathrm{~mL}$ bone marrow was harvested from the iliac crests of an adult beagle dog, transferred into a $10 \mathrm{~mL}$ preheparinized centrifuge tube, and centrifuged to remove fat and heparin. Mononuclear cBMSCs were separated by percoll $(1.073 \mathrm{~g} / \mathrm{mL}$, Sigma, USA) gradient centrifugation [24] and cultured in a complete medium containing low glucose-Dulbecco's modified Eagle's medium (L-DMEM; Gibco, USA) with 10\% fetal bovine serum (FBS; Hyclone, USA) and $100 \mathrm{U} / \mathrm{mL}$ streptomycin at a density of $5 \times 10^{4} / \mathrm{cm}^{2}$. Cells were incubated at $37^{\circ} \mathrm{C}$ in a humidified atmosphere containing $5 \% \mathrm{CO}_{2}$. The culture medium was refreshed after $48-72 \mathrm{~h}$ and then every 
2-3 days. When $80-90 \%$ cell confluence was reached, the cells were detached with $0.25 \%$ trypsin containing $0.01 \%$ EDTA (Invitrogen, USA) and then subcultured.

For cell osteogenic differentiation, the fourth-generation cBMSCs were cultured in medium containing high glucoseDMEM (H-DMEM, Life Technologies, Inc., USA) with 10\% FBS, 100 nM dexamethasone (Sigma-Aldrich Co. Ltd., USA), $10 \mathrm{mM} \beta$-sodium glycerophosphate (Sigma, USA), and $200 \mu \mathrm{M}$ ascorbic acid (Sigma-Aldrich Co. Ltd., USA). The medium was replaced every 2 days. All animal care and procedures were done in accordance with the Animal Care Guidelines from Chinese People's Liberation Army General Hospital's Animal ethics committee.

\subsection{In Vitro Biocompatibility}

2.5.1. Cytotoxicity Assay. The cytotoxicity assay was conducted by culturing cBMSCs in the extracts of the CSH and $\mathrm{Mg} / \mathrm{CSH}$ composite specimens and using a 3-(4,5-dimethylthiazol-2-yl)-2,5-diphenyltetrazolium bromide (MTT) (Sigma-Aldrich Co. Ltd., USA) quantitative proliferation assay. According to ISO 10993-1: Biological evaluation of medical devices Part 1: Evaluation and testing within a risk management process, $0.2 \mathrm{~g} / \mathrm{mL}$ extracts were prepared by soaking cements in cell culture medium for 1 day at $37^{\circ} \mathrm{C}, 5 \%$ $\mathrm{CO}_{2}$ (10 mL extract for each cement). The third-generation cBMSCs after osteogenic differentiation were detached by $0.25 \%$ trypsin, and then cell suspension was transferred to 96-well plates (volume: $200 \mu \mathrm{L} /$ well, density: $5 \times 10^{4} / \mathrm{mL}$ ). Six wells were set for each cement group. After incubation at $37^{\circ} \mathrm{C}$ in a humidified atmosphere of $5 \% \mathrm{CO}_{2}$ for $24 \mathrm{~h}, \mathrm{cBMSCs}$ were cultured in the presence of $100 \mu \mathrm{L}$ extracts, and afterwards the medium was refreshed every 2 days. After 2, 4, 6, and 8 days, $20 \mu \mathrm{L}$ MTT $(5 \mathrm{~g} / \mathrm{L})$ was added into each well, and cBMSCs were incubated for further $4 \mathrm{~h}$. Subsequently, the supernatant in each well was carefully removed and $150 \mu \mathrm{L}$ dimethyl sulfoxide was added. After shaking for $10 \mathrm{~min}$, optical density (OD) values at $490 \mathrm{~nm}$ were evaluated by using a microplate reader.

2.5.2. Proliferation of cBMSCs and Cell Cycle Test Based on Flow Cytometry. The proliferation of cBMSCs seeded on the pure $\mathrm{CSH}$ and $\mathrm{Mg} / \mathrm{CSH}$ composite cements was evaluated by using cell cycle test based on flow cytometry. After 24, 48 , and $72 \mathrm{~h}$ of incubations, cBMSCs were collected with trypsinization and centrifugation at $1000 \mathrm{rpm}$ and washed twice with PBS. Then, cBMSCs were resuspended in PBS, fixed in $70 \%$ ethanol at $4^{\circ} \mathrm{C}$ for overnight. Finally, samples were centrifuged and stained with $0.5 \mathrm{~mL}$ hypotonic solution containing $50 \mu \mathrm{g} / \mathrm{mL}$ PI, $0.2 \%$ Triton X-100, and $100 \mu \mathrm{g} / \mathrm{mL}$ RNase A for $30 \mathrm{~min}$ in dark at $4^{\circ} \mathrm{C}$. The numbers of cell at different phases of cell cycle were analyzed by using a flow cytometer at $488 \mathrm{~nm}$ excitation band. The proliferation index of cell was calculated as follows: Proliferation index $=(\mathrm{S}+$ $\mathrm{G} 2 \mathrm{M}) /(\mathrm{G} 0 \mathrm{G} 1+\mathrm{S}+\mathrm{G} 2 \mathrm{M}) \times 100 \%$.

2.5.3. Osteogenic Differentiation and Alkaline Phosphatase (ALP) Biosynthesis. For osteogenic differentiation, the biosynthesis of ALP in cBMSCs cultured on the pure CSH and
TABLE 1: The sequences of the primers used for qRT-PCR.

\begin{tabular}{|c|c|}
\hline Gene & Primer sequence \\
\hline \multirow{2}{*}{ Integrin $\beta 1$} & F5'-GTGCTGAAGACTACCCCATC \\
\hline & R5'-CTCCACAAAAGAGCCAAATC \\
\hline \multirow{2}{*}{ Type I collagen } & F5'-ATGGATGAGGAAACTGGC \\
\hline & R5'-TCAAGGAAGGGCAAACG \\
\hline \multirow{2}{*}{ Osteopontin } & F5'-AACCACAGTTTTCACTGAAGTCGT \\
\hline & R5'-TCCAAGTCCTCGCTGTCCAC \\
\hline \multirow{2}{*}{ BMP-2 } & F5'-GGGTATCACGCCTTTTACTGC \\
\hline & R5'-TCGGAATCTTAGAGTTCACGGA \\
\hline \multirow{2}{*}{$\beta$-actin } & F5'-GTGATGGTGGGCATGGGTC \\
\hline & R5'-GATTCGTGCTCGATGGGGTA \\
\hline
\end{tabular}

$\mathrm{Mg} / \mathrm{CSH}$ composite cements was measured. After 7, 14, 21, and 28 days of incubation, culture medium was wiped off, and cBMSCs were washed twice with PBS. Approximately $1 \mathrm{~mL}$ of cell lysis buffer containing $0.2 \%$ Triton X-100 was added to lyse cBMSCs at room temperature, and cell lysate was obtained. After centrifugation, exactly $100 \mu \mathrm{L}$ of supernatant was moved to 96 -well plates, and $100 \mu \mathrm{L}$ p-nitrophenyl phosphate (pNPP, $1 \mathrm{mg} / \mathrm{mL}$ ) substrate solution was added. After incubation for $30 \mathrm{~min}$ at $37^{\circ} \mathrm{C}$, the reaction was quenched by adding $50 \mu \mathrm{L} \mathrm{NaOH}$, and the absorbance at $405 \mathrm{~nm}$ was quantified with a plate reader. Each test was conducted five times.

2.5.4. Cellular Morphology and Attachment of cBMSCs. The cellular morphology and attachment of cBMSCs were examined based on direct visualization under SEM. Firstly, cells were attached to the specimens for 3,7 , and 14 days at $37^{\circ} \mathrm{C}$ in an atmosphere of $100 \%$ humidity and $5 \% \mathrm{CO}_{2}$. Subsequently, the cell-cement constructs were washed twice with PBS and fixed with $2.5 \%$ glutaraldehyde solution for $2 \mathrm{~h}$ at $4^{\circ} \mathrm{C}$. Then, the fixed constructs were rinsed three times with PBS and dehydrated in graded ethanol (v/v: 50, 60, 70, 80, 90, and $100 \%)$. After being $\mathrm{CO}_{2}$-dried overnight in a desiccator, samples were sputtered with gold prior to SEM observation.

2.5.5. Expressions of Osteogenesis and Attachment-Related Genes. The relative expressions of osteogenesis and attachment-related genes in cBMSCs were examined by using real-time RT-PCR (Thermo, USA). After being cultured on the hardened constructs for 8,24 , and $48 \mathrm{~h}, \mathrm{cBMSCs}$ were homogenized in Trizol Reagent. Total RNA was extracted and reversely transcribed into cDNA according to the manufacturer's instructions. The sequences of primers for type I collagen (Coll I), integrin $\beta 1$, and $\beta$-actin are shown in Table 1. The SYBR Green real-time PCR assay was carried out to measure the expression of genes according to its manual. Relative expression of each target gene was evaluated via the $2^{-\Delta \Delta \mathrm{CT}}$ method [25].

2.6. Implantation In Vivo. Totally, 24 healthy adult male beagle dogs weighing $16 \pm 1 \mathrm{~kg}$ were randomly divided into 4 groups (6 dogs for each type of implant). The dogs were anesthetized through $3 \%$ pentobarbital (general anaesthesia) and $1 \%$ lidocaine (operative region anaesthesia) and placed in 


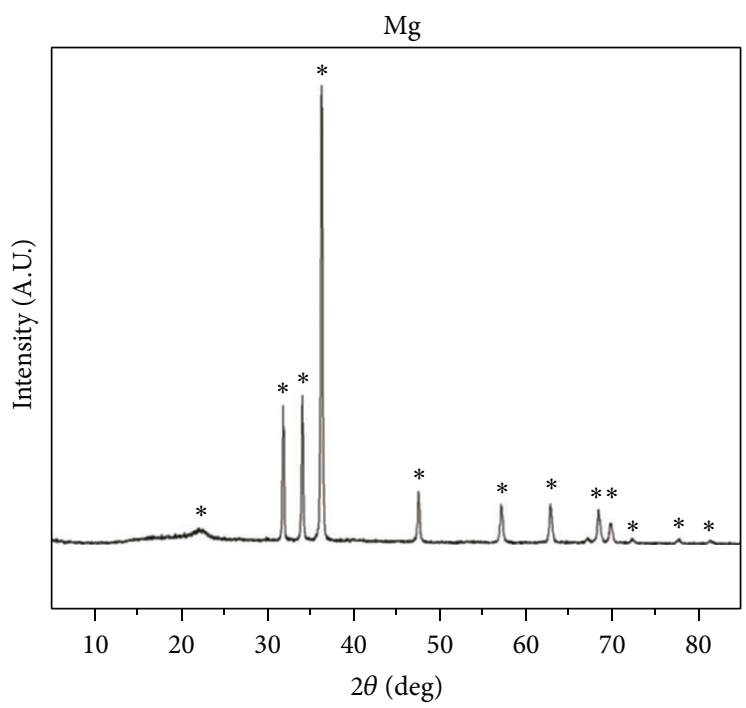

(a)

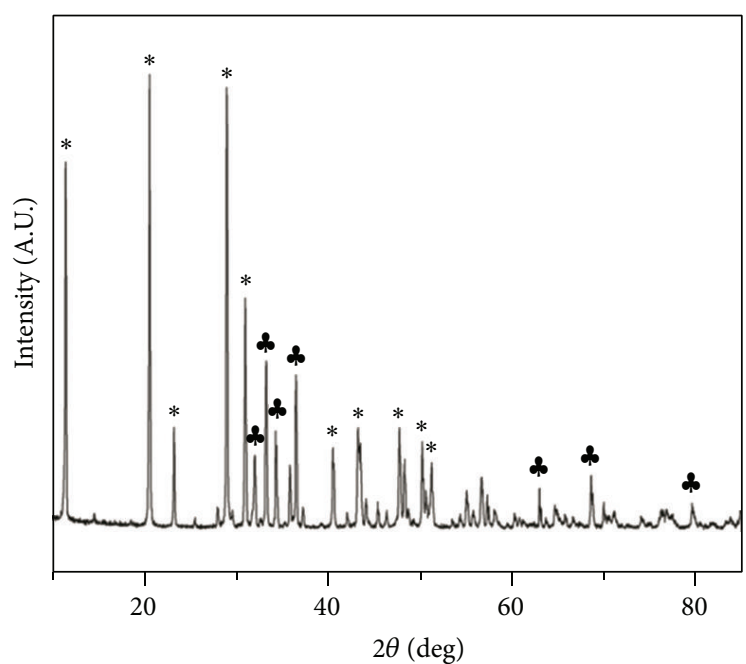

* $\mathrm{CaSO}_{4} 2 \mathrm{H}_{2} \mathrm{O}$

+ $\mathrm{Mg}$

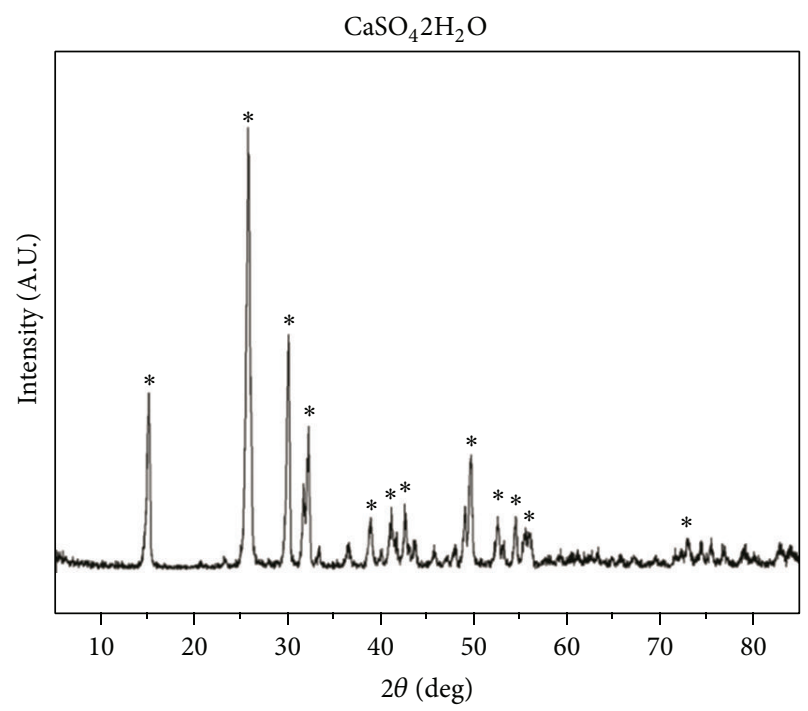

(b)

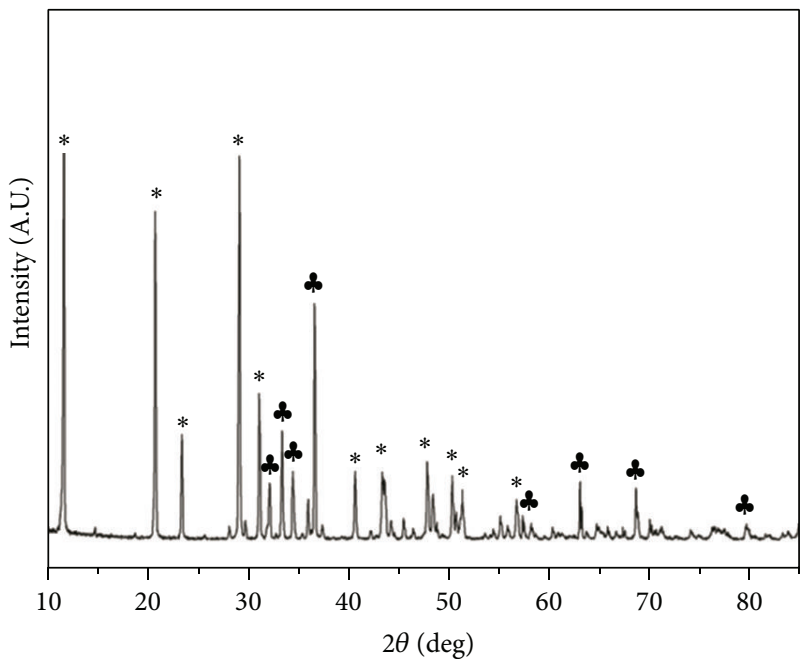

* $\mathrm{CaSO}_{4} 2 \mathrm{H}_{2} \mathrm{O}$

\& $\mathrm{Mg}$

(c)

(d)

Figure 1: X-ray diffraction patterns after setting for $24 \mathrm{~h}$. (a) Mg; (b) CSH; (c) 10\% Mg/CSH composite; (d) 20\% Mg/CSH composite. Mg: magnesium; CSH: calcium sulfate hemihydrate.

a supine position. Under sterile conditions, a $3 \mathrm{~cm}$ longitudinal skin incision was performed at the anteromedial aspect of left tibia. Skin and subcutaneous tissues were gently dissected down to periosteum, exposing the bone. Then, one tibial bone tunnel (3 $\mathrm{mm}$ diameter and $15 \mathrm{~mm}$ length) was surgically produced. The defects were filled with $20 \% \mathrm{Mg} / \mathrm{CSH}, 10 \%$ $\mathrm{Mg} / \mathrm{CSH}$, or pure $\mathrm{CSH}$ construct, and bone defects of the control group were left unfilled. All wounds were routinely sutured and penicillin $(25,000 \mathrm{U} / \mathrm{kg})$ was injected into all animals for 3 days. After surgery, the canines were kept caged freely and given usual regimen of food and water.

Animals were sacrificed 4 and 12 weeks after operation and tibia specimens were harvested and fixed in $4 \%$ paraformaldehyde. The local bone mineral densities (BMDs) were measured on a dual energy X-ray absorptiometry (DXA) system, and the new bone area fraction (BAF) was quantified 1 day and 4 and 8 weeks after implantation by using the following formula: $\mathrm{BAF}=\mathrm{AB} / \mathrm{AT}$, where $\mathrm{AB}$ is the newly formed bone area and AT is the total material area. For histological analysis after 4, 8, and 12 weeks after surgery, the decalcified and undecalcified bone specimens were, respectively, embedded into paraffin and hard plastic. Tissue sections were stained with hematoxylin and eosin (H\&E) and Masson's Trichrome stain, respectively, and then observed under a light microscope (Olympus BX51, Japan). Additionally, the tissue specimens $(5 \mathrm{~mm} \times 5 \mathrm{~mm} \times 5 \mathrm{~mm}$ ) around the implantation materials were removed and immediately immersed into RNAlater solution. Then, the total 


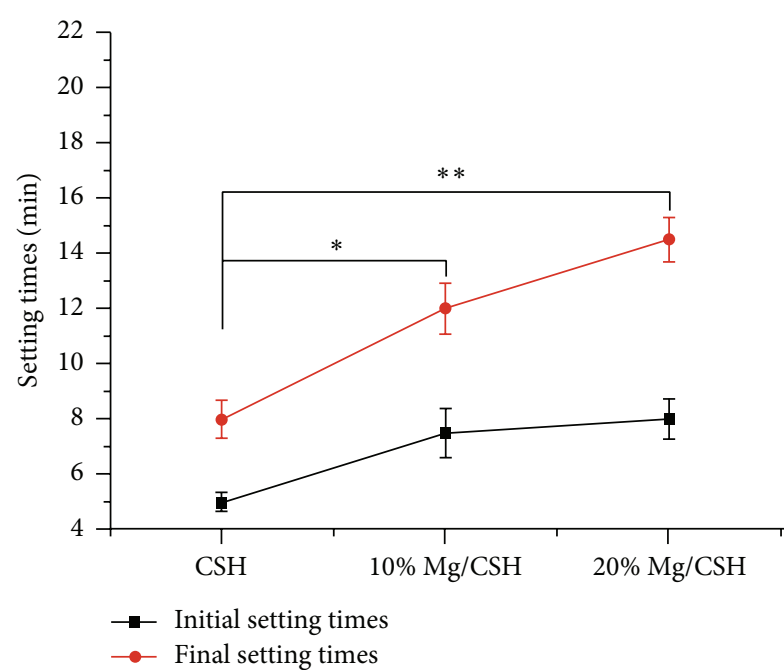

(a)

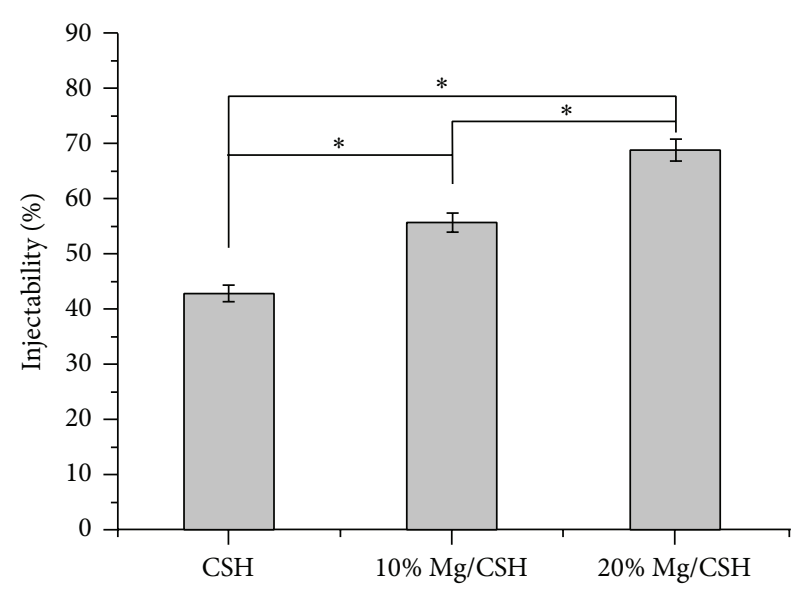

(b)

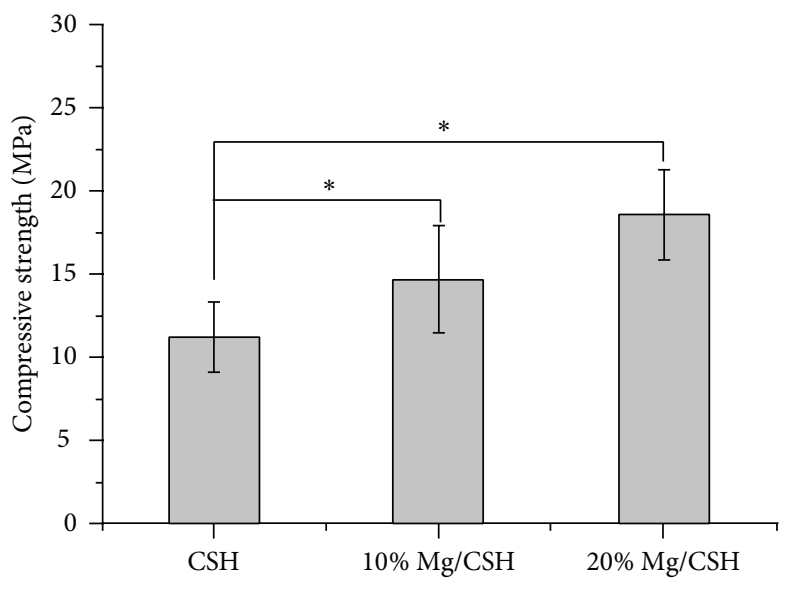

(c)

FIGURE 2: The setting time, injectability, and compressive strength of CSH and Mg/CSH composite specimens. (a) The initial and final setting time; (b) injectability; (c) compressive strength after setting for $24 \mathrm{~h} .{ }^{*} p<0.05$ and ${ }^{* *} p<0.01$ indicate that the setting time, injectability, and compressive strength of $\mathrm{Mg} / \mathrm{CSH}$ composite specimens were significantly different from those of $\mathrm{CSH}$. The bars on the graphs are standard deviations. Mg: magnesium; CSH: calcium sulfate hemihydrate.

tissular RNA was extracted and reverse-transcribed into cDNA, and the transcription levels of osteogenesis-related canine osteopontin, bone morphogenetic protein-2 (BMP-2), and Coll I were measured by RT-PCR.

2.7. Statistical Analysis. Experimental data were expressed as means \pm SD. The one-way and two-way ANOVA with Tukey's post hoc tests were applied to comparison analysis. Differences were considered statistically significant at $p<0.05$.

\section{Results}

3.1. Characterization of $\mathrm{Mg} / \mathrm{CSH}$. After setting for $24 \mathrm{~h}$, the phase composition of the hardened $\mathrm{Mg} / \mathrm{CSH}$ composite was characterized by using XRD. The CSH construct contained diffraction peaks of $\mathrm{CaSO}_{4} \cdot 2 \mathrm{H}_{2} \mathrm{O}$ (Figure 1(b)), and a mixture of $\mathrm{CaSO}_{4} \cdot 2 \mathrm{H}_{2} \mathrm{O}$ and $\mathrm{Mg}$ could be seen in the XRD patterns of the $\mathrm{Mg} / \mathrm{CSH}$ composites with $10 \%$ and $20 \% \mathrm{Mg}$ (Figures 1 (c) and $1(\mathrm{~d})$ ). The presence of $\mathrm{CaSO}_{4} \cdot 2 \mathrm{H}_{2} \mathrm{O}$ could be attributed to the reaction of $\mathrm{CaSO}_{4} \cdot 1 / 2 \mathrm{H}_{2} \mathrm{O}$ and $\mathrm{H}_{2} \mathrm{O}$.

3.2. Setting Time, Injectability, and Compressive Strength of $\mathrm{Mg} / \mathrm{CSH}$. The initial and final setting time of $10 \%$ and $20 \%$ $\mathrm{Mg} / \mathrm{CSH}$ composites were significantly higher than those of pure $\mathrm{CSH}$, and setting time increased with increasing weight ratio of Mg. The longest setting time $(p<0.01)$ was observed in $20 \% \mathrm{Mg} / \mathrm{CSH}$ composite with the initial and final setting time of $8 \pm 0.72 \mathrm{~min}$ and $14.5 \pm 0.8 \mathrm{~min}$, respectively (Figure 2(a)). The injectability of $\mathrm{Mg} / \mathrm{CSH}$ composite pastes was significantly improved in comparison with that of $\mathrm{CSH}$ paste $(p<0.05)$. Moreover, the injectability of $\mathrm{Mg} / \mathrm{CSH}$ composite pastes dramatically increased with the increase of $\mathrm{Mg}$ content, and $20 \% \mathrm{Mg} / \mathrm{CSH}$ composite paste exhibited the highest injectability $(69 \pm 2 \%, p<0.05)$ (Figure 2(b)). After setting for $24 \mathrm{~h}$, the compressive strength of the hardened constructs also significantly rose $(p<0.05)$ with 

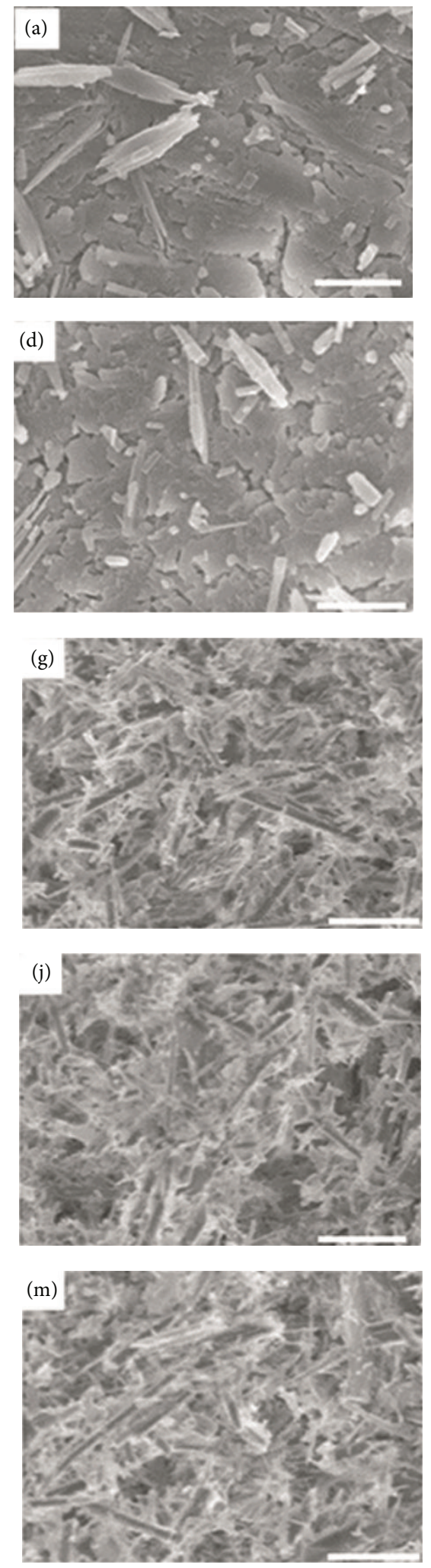
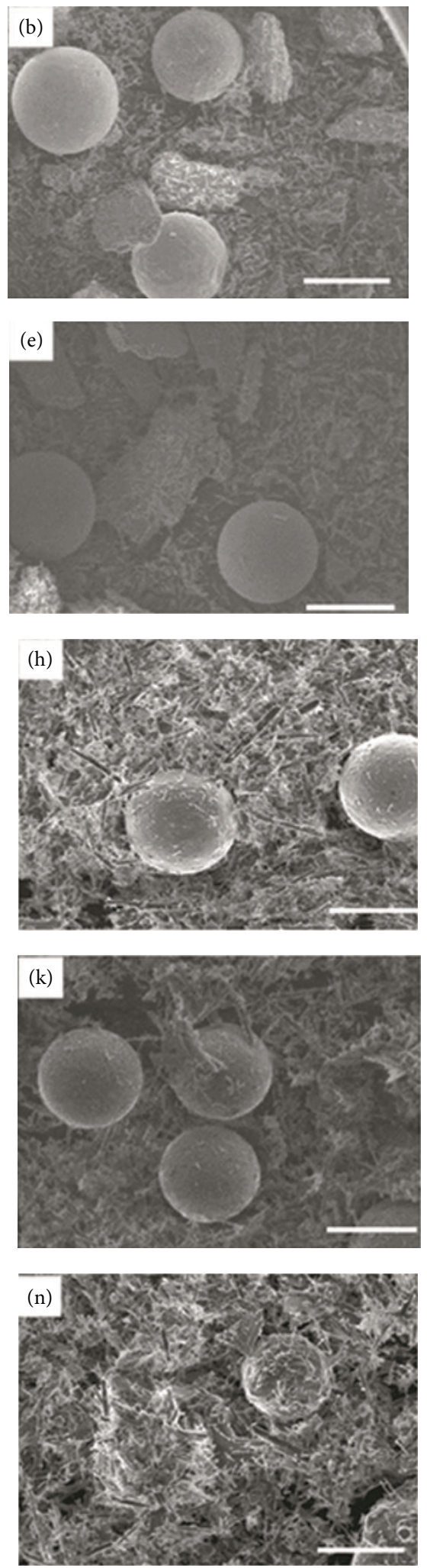

Figure 3: Continued.
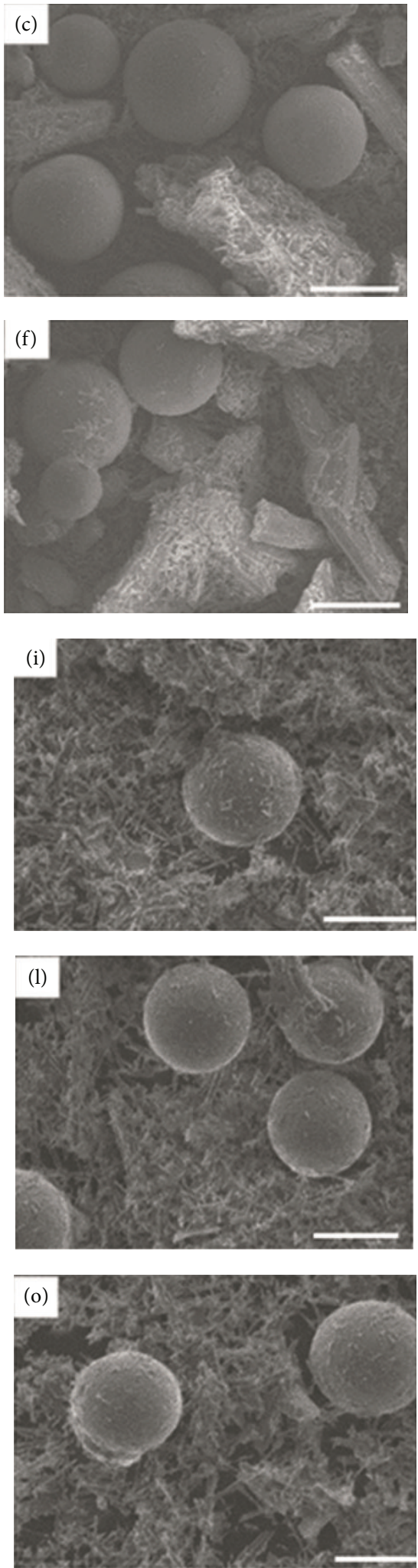

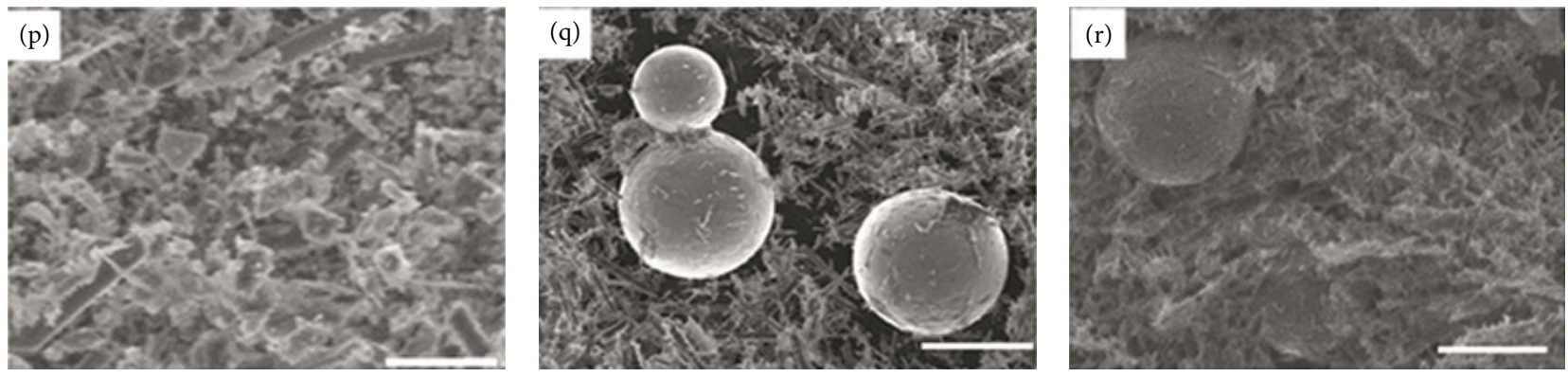

FIGURE 3: Scanning electron microscope micrographs of the CSH and $\mathrm{Mg} / \mathrm{CSH}$ composite specimens after soaking in simulated body fluid for different time. CSH (a), $10 \% \mathrm{Mg} / \mathrm{CSH}$ (b) and $20 \% \mathrm{Mg} / \mathrm{CSH}$ (c) for after 2 days. CSH (d), $10 \% \mathrm{Mg} / \mathrm{CSH}$ (e) and $20 \% \mathrm{Mg} / \mathrm{CSH}$ (f) for after 4 days. CSH (g), 10\% Mg/CSH (h) and $20 \% \mathrm{Mg} / \mathrm{CSH}$ (i) for after 7 days. CSH (j), 10\% Mg/CSH (k) and 20\% Mg/CSH (l) for after 10 days. CSH (m), $10 \% \mathrm{Mg} / \mathrm{CSH}(\mathrm{n})$ and $20 \% \mathrm{Mg} / \mathrm{CSH}$ (o) for after 14 days. CSH (p), $10 \% \mathrm{Mg} / \mathrm{CSH}$ (q) and 20\% Mg/CSH (r) for after $21 \mathrm{days.}$ Magnification: $\times 500$. Scale bar: $50 \mu \mathrm{m}$.

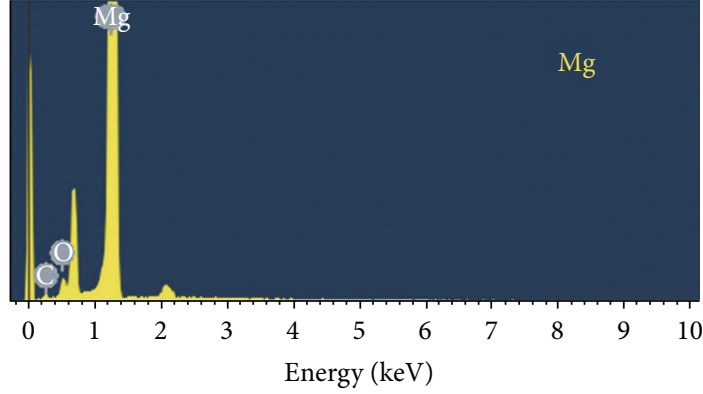

(a)

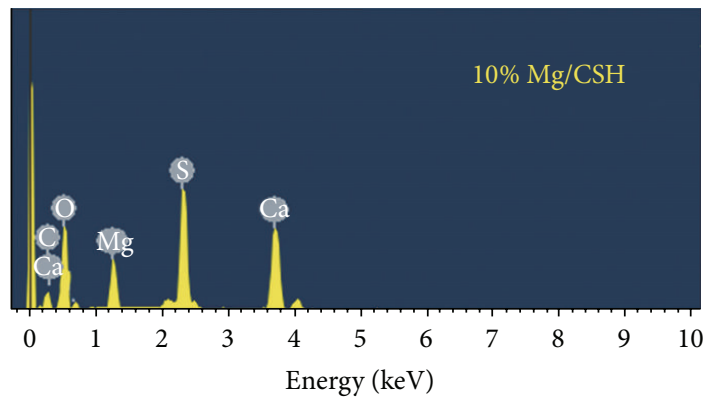

(c)

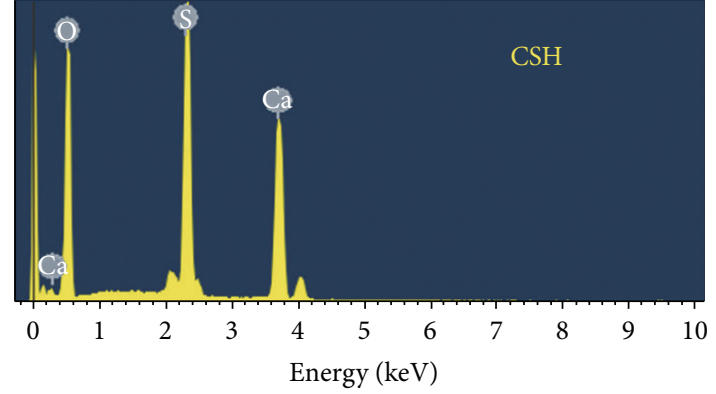

(b)

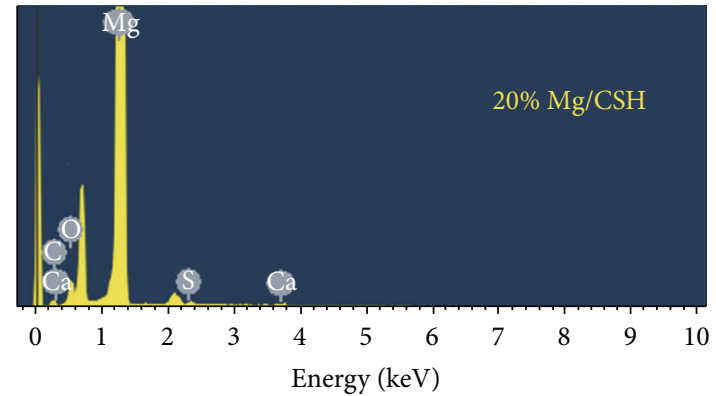

(d)

FIGURE 4: EDX analysis of specimens immersed in simulated body fluid for 21 days. (a) Mg; (b) CSH; (c) 10\% Mg/CSH composite; (d) 20\% $\mathrm{Mg} / \mathrm{CSH}$ composite. EDX: energy dispersive X-ray detector; Mg: magnesium; CSH: calcium sulfate hemihydrate.

the increase of $\mathrm{Mg}$ content and reached a maximum value of $18.6 \pm 2.7 \mathrm{MPa}$ in $20 \% \mathrm{Mg} / \mathrm{CSH}$ composite, while there is no significant difference $(p>0.05)$ between $10 \% \mathrm{Mg} / \mathrm{CSH}$ and $20 \% \mathrm{Mg} / \mathrm{CSH}$ composites (Figure 2(c)).

3.3. In Vitro Bioactivity, Degradation, and $p H$ Value Change in SBF. SEM micrographs of surface showed the influence of SBF on the microstructure of materials (Figure 3). After soaking for 2 and 4 days, vast ribbed crystals were observed in the CSH specimens (Figures 3(a) and 3(d)). With long immersion time, a sediment layer was formed on the surface (Figures 3(g), 3(j), 3(m), and 3(p)). For the $\mathrm{Mg} / \mathrm{CSH}$ composite specimens, ball-like $\mathrm{Mg}$ particles and $\mathrm{CaSO}_{4}$ crystals were displayed after 2 and 4 days of immersion (Figures 3(b)$3(c)$ and 3(e)-3(f)). Subsequently, many sediments formed and further congregated to form a layer on the surface of sample, while $\mathrm{Mg}$ particles showed no obvious change (Figures 3(e)-3(f), 3(h)-3(i), 3(k)-3(l), 3(n)-3(o), and 3(q)$3(\mathrm{r})$ ). There was no obvious difference between the surfaces of $10 \%$ and $20 \% \mathrm{Mg} / \mathrm{CSH}$ composites after immersion. EDX indicated that the surfaces of pure $\mathrm{Mg}$ contained $\mathrm{Mg}, \mathrm{C}$, and $\mathrm{O}$ ions (Figure 4(a)), and $\mathrm{CSH}$ cement had some O, S, and Ca (Figure $4(\mathrm{~b})$ ). The $10 \%$ and $20 \% \mathrm{Mg} / \mathrm{CSH}$ composite samples consisted mainly of $\mathrm{Mg}, \mathrm{C}, \mathrm{O}, \mathrm{S}$, and $\mathrm{Ca}$ (Figures 4(c) and $4(\mathrm{~d}))$ after soaking for 21 days.

The degradation ratios of the samples were characterized by the weight loss ratios after soaking in SBF for various time 


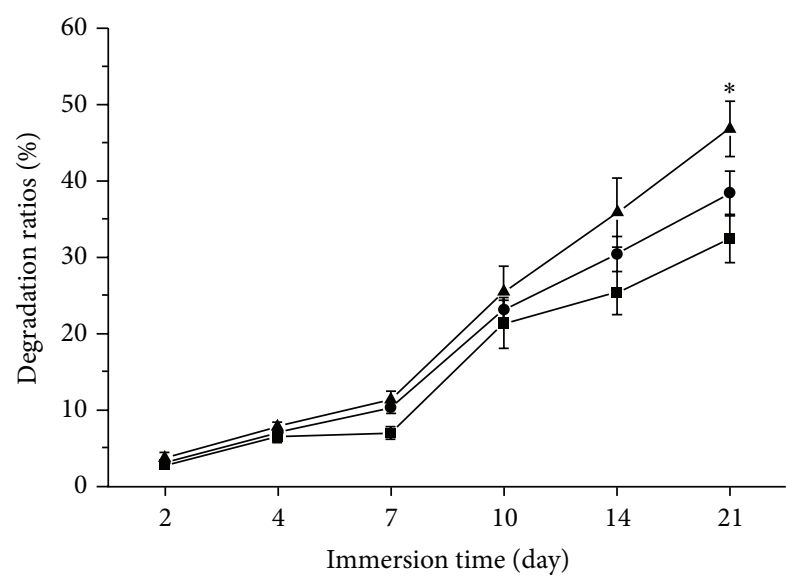

(a)

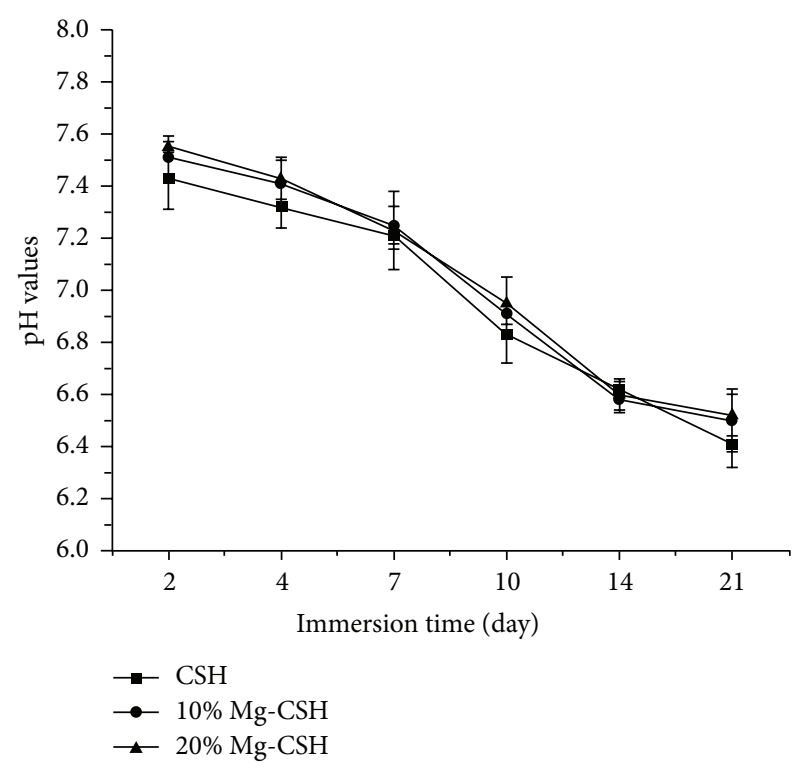

(b)

FIGURE 5: Degradation ratios of $\mathrm{CSH}$ and $\mathrm{Mg} / \mathrm{CSH}$ composite specimens immersed for 2, 4, 7, 10, 14, and 21 days. (a) Simulated body fluid; (b) $\mathrm{pH}$ values of the environment. * indicates that degradation ratios of the $\mathrm{Mg} / \mathrm{CSH}$ composite specimens were significantly different from those of $\mathrm{CSH}(p<0.05)$. The bars on the graphs are standard deviations. Mg: magnesium; CSH: calcium sulfate hemihydrate.

periods. It can be seen that there were no significant differences $(p>0.05)$ in the degradation ratios among all specimens from 2 to 14 days, while the degradation ratio of $20 \%$ $\mathrm{Mg} / \mathrm{CSH}$ composite was significantly higher $(p<0.05)$ than that of other constructs after 21 days of soaking (Figure 5(a)). During immersion in SBF, the samples led to an acid environment, causing a decrease in the $\mathrm{pH}$ values of SBF. However, no remarkable difference $(p>0.05)$ was observed among the three kinds of construct at selected time points (Figure 5(b)).

3.4. Viability, Proliferation, Differentiation, Attachment, and Morphology of cBMSCs after Incubation with Biomaterials. Changes of the viability of cBMSCs cultured in different extracts were assessed through MTT assay. It was observed that the OD values in all extracts increased with time, indicating that three constructs caused no significant cytotoxicity against cells during various time periods. However, the viability of cBMSCs in the extracts of both $10 \%$ and $20 \%$ $\mathrm{Mg} / \mathrm{CSH}$ composite specimens was significantly higher $(p<$ $0.05)$ than that of cBMSCs in the extracts of pure CSH after incubating for 8 days (Figure 6(a)).

No significant difference $(p>0.05)$ was observed among the proliferation indexes of cBMSCs cultured on different materials for 24 and $48 \mathrm{~h}$. However, the $\mathrm{Mg} / \mathrm{CSH}$ composites $(10 \%$ and $20 \%)$ could significantly $(p<0.05)$ increase cell proliferation when compared with the CSH after $72 \mathrm{~h}$ of culture (Figure 6(b)).

Cellular differentiation was evaluated by testing the ALP activity of cBMSCs cultured on construct specimens for 7, 14,21 , and 24 days. The ALP activities of cells grown on all three materials were elevated with time, while there was no significant difference $(p>0.05)$ among ALP activities of cBMSCs in three groups at a certain time point (Figure 6(c)).
The cells firmly attached and exhibited morphologically normal appearance on the surface of $10 \% \mathrm{Mg} / \mathrm{CSH}$ and $\mathrm{CSH}$ constructs after 3 days of culture (Figures 7(a) and 7(d)). Cells extended and spread well after 7 days of culture (Figures 7(b) and $7(\mathrm{e}))$, ultimately forming a confluent layer with intimate attachment to the material surface in 14 days (Figures 7(c) and $7(\mathrm{f}))$.

The relative expression values of integrin $\beta 1$ gene were dramatically increased $(p<0.05)$ in cBMSCs cultured on $\mathrm{Mg} / \mathrm{CSH}$ composites (10\% and $20 \%$ ) in comparison with $\mathrm{CSH}$ construct, while no significant difference $(p>0.05)$ was observed between $10 \%$ and $20 \% \mathrm{Mg} / \mathrm{CSH}$ at 8,24 , and $48 \mathrm{~h}$ (Figure 8(a)). The Coll I expressions showed similar trends (Figure 8(b)).

3.5. In Vivo DXA Analysis. To quantify the calcification of repaired tibia, BMDs of all animals were measured on DXA 4 and 12 weeks after operation. The $\mathrm{Mg} / \mathrm{CSH}$ grafts showed higher $(p<0.05)$ BMD values than CSH and control groups at both 4 and 12 weeks. However, there was no marked variation $(p>0.05$ ) between $10 \%$ and $20 \% \mathrm{Mg} / \mathrm{CSH}$ grafts (Figure 9(a)). Meanwhile, BAF was applied to evaluate the newly formed bone after surgery for $1 \mathrm{~d}$ and 4 and 8 weeks. The BAFs of $\mathrm{Mg} / \mathrm{CSH}$ composite graft were significantly higher $(p<0.05)$ than that of CSH at both 4 and 8 weeks (Figure 9(b)).

3.6. In Vivo Histological Analysis. After 4 weeks' implantation, new chondrocytes appeared in many areas of the $10 \%$ $\mathrm{Mg} / \mathrm{CSH}$ composite implant and some inflammatory cells could be seen in the center of bone defect area (Figure 10(a)). The cellular differentiation appeared at 8 weeks (Figure 10(b)) and more cells gathered in fascicles at the interface between 


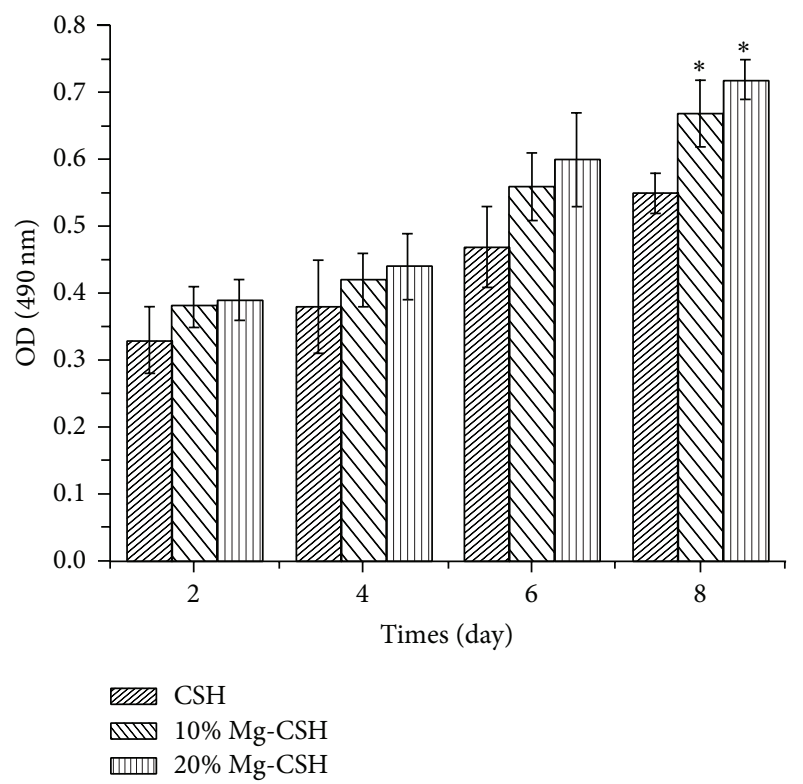

(a)

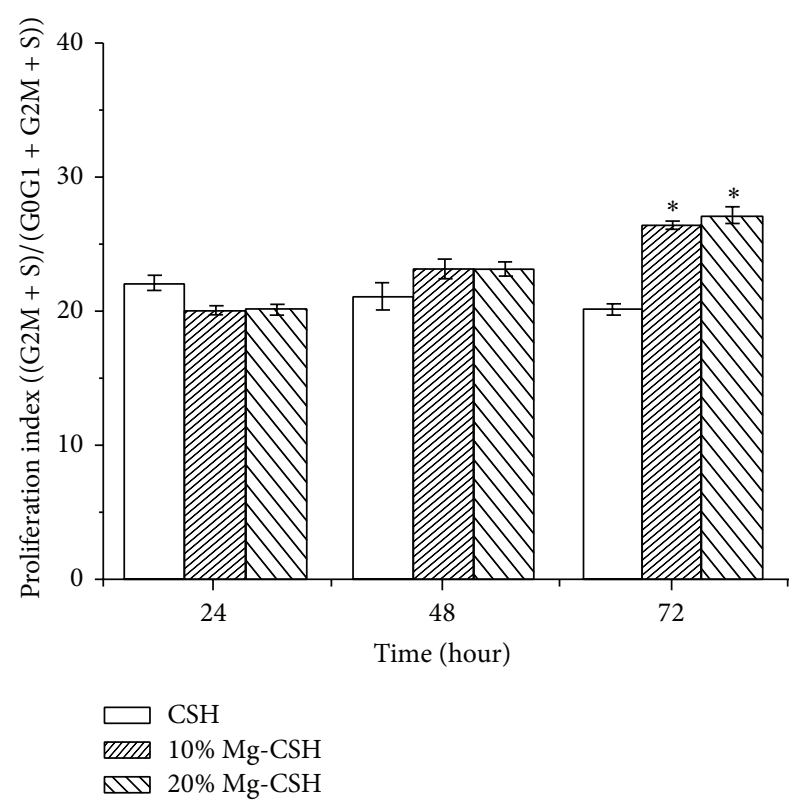

(b)

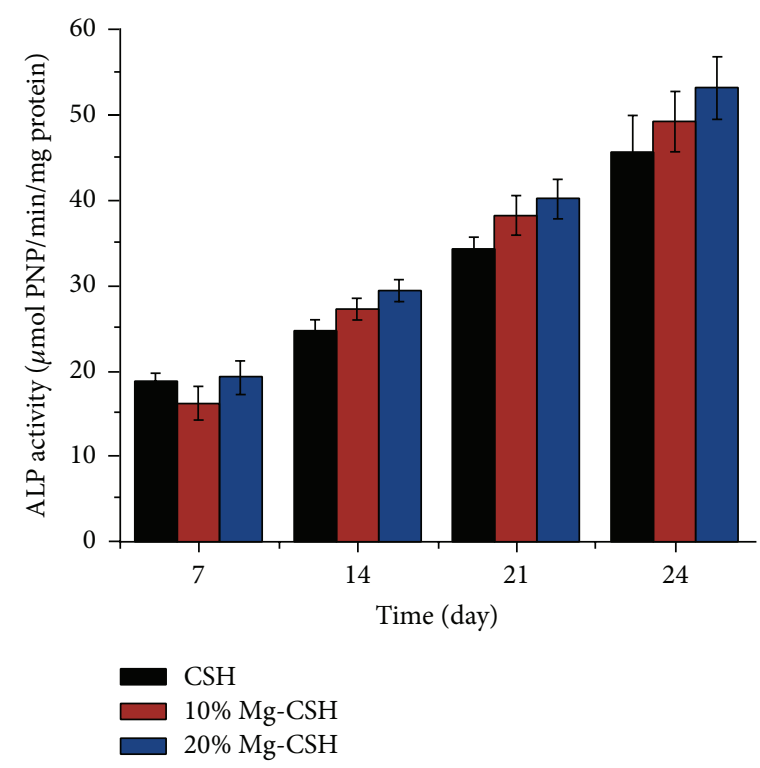

(c)

FIGURE 6: Cell viability, proliferation index, and alkaline phosphatase activity. (a) Cell viability incubated with the extraction fluids of CSH and $\mathrm{Mg} / \mathrm{CSH}$ composite specimens after 2, 4, 6, and 8 days; (b) proliferation index cultured on CSH and $\mathrm{Mg} / \mathrm{CSH}$ composite specimens after 24, 48, and $72 \mathrm{~h}$; (c) ALP activity of cells cultured on CSH and Mg/CSH composite specimens after 7, 14, 21, and 24 days. * indicates that the cell viability and proliferation index of $\mathrm{Mg} / \mathrm{CSH}$ composite specimens were significantly different from those of CSH $(p<0.05)$. The bars on the graphs are standard deviations. Mg: magnesium; CSH: calcium sulfate hemihydrate; ALP: alkaline phosphatase.

the implant materials and the host bone after 8 weeks (Figure 10(c)). Masson staining showed no new bone tissue was observed at the interface of CSH implant after 4 (Figure 10(d)) and 8 (Figure 10(e)) weeks, while new trabeculae could be seen in the implanted $10 \% \mathrm{Mg} / \mathrm{CSH}$ composite section at 8 weeks (Figure $10(\mathrm{~g})$ ).

Undecalcified bone histology can preferably demonstrate cellular components of bone, bone turnover, and formation. New chondrocytes were still seen in the implant areas of $10 \%$
$\mathrm{Mg} / \mathrm{CSH}$ at 4-16 weeks (Figures 11(a)-11(c)) in accordance with the decalcified staining results. Moreover, the boundaries between normal surrounding tissue and the composite specimens were gradually indistinct due to biodegradation, and the residual materials were surrounded by areas of newly formed bone tissue during 4-12 weeks (Figures 11(d)-11(f)).

3.7. Analysis of Gene Expression. The relative expression levels of osteopontin among the tissues around three graft 

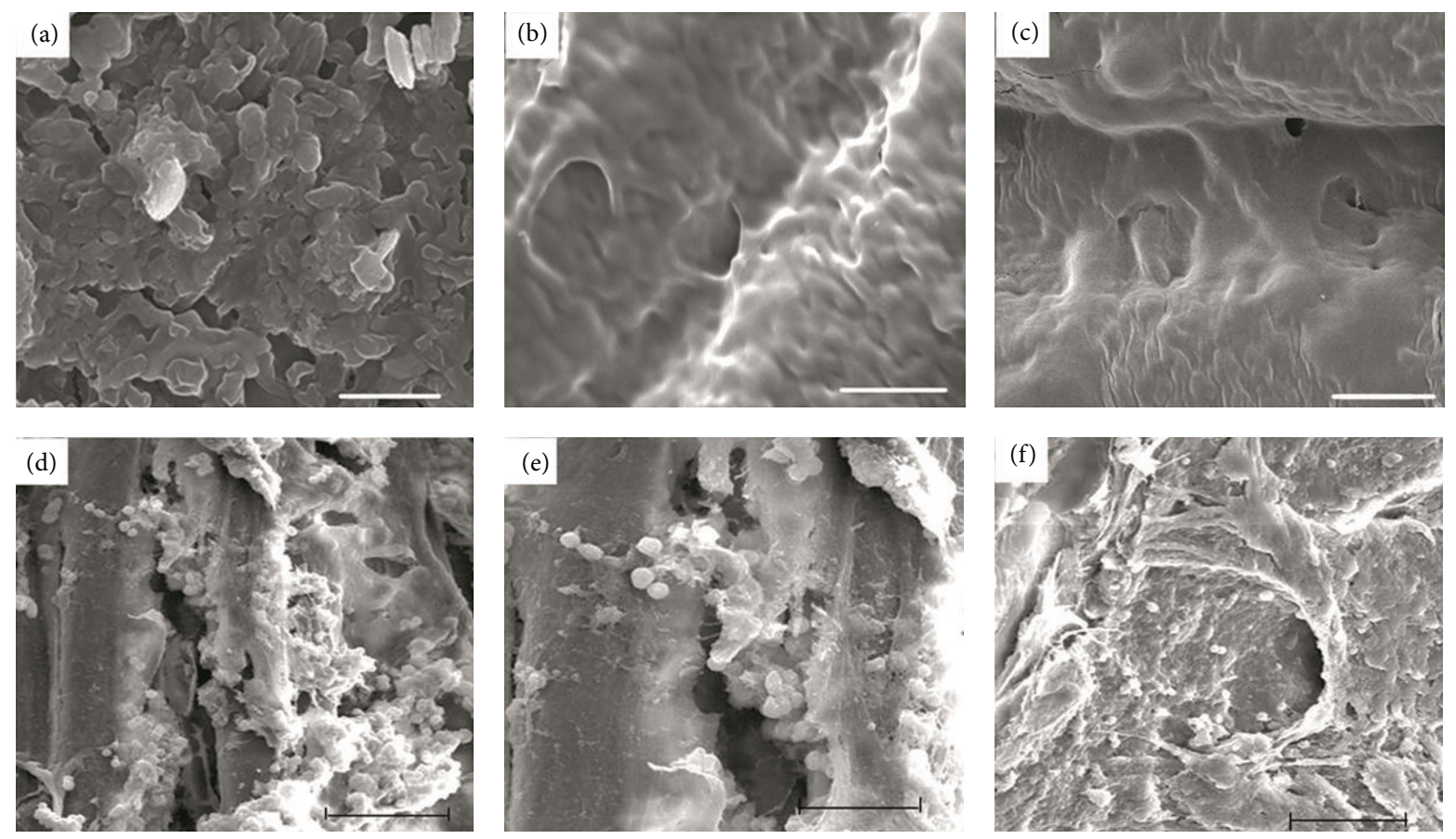

FIGURE 7: Scanning electron microscope micrographs showing the morphological features of cells cultured on CSH and Mg/CSH composite specimens. Images of cells cultured on CSH (a) and 10\% Mg/CSH composite specimens (d) for 3 days; images of cells cultured on CSH (b) and $10 \% \mathrm{Mg} / \mathrm{CSH}$ composite specimens (e) for 7 days; images of cells cultured on CSH (c) and 10\% Mg/CSH composite specimens (f) for 14 days. Magnification: $\times 500$. Scale bar: $50 \mu \mathrm{m}$. Mg: magnesium; CSH: calcium sulfate hemihydrate.

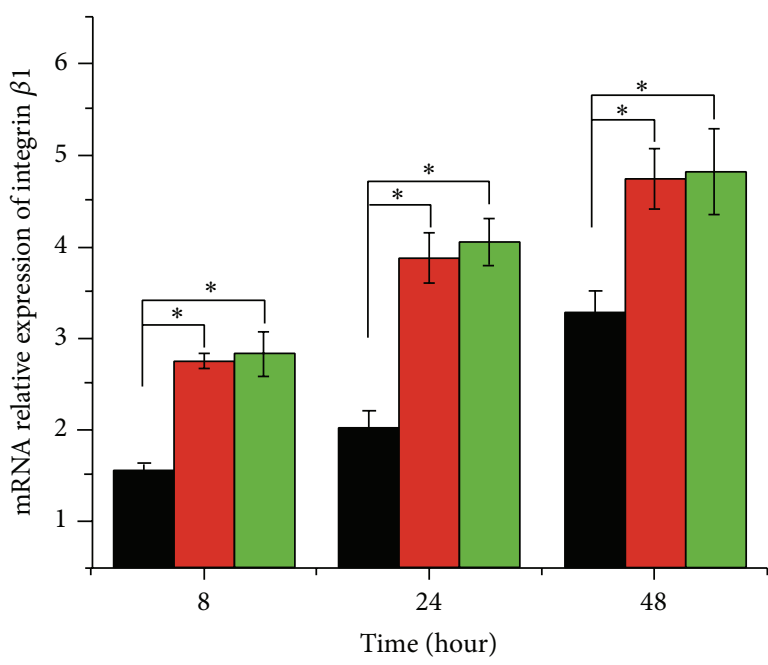

Time (hour)

(a)

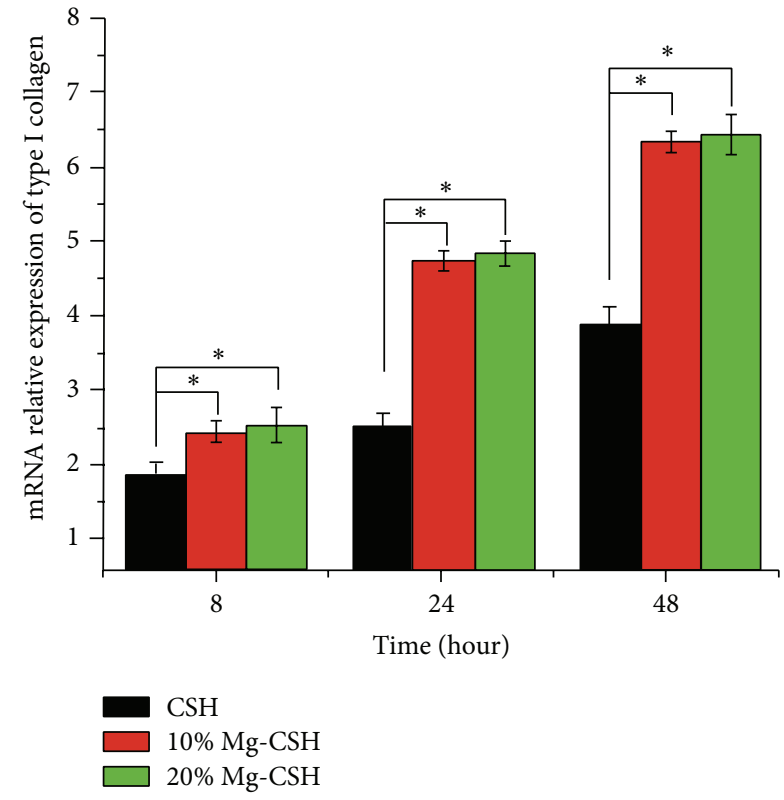

(b)

FIGURE 8: mRNA relative expressions of integrin $\beta 1$ and type I collagen. (a) Integrin $\beta 1$; (b) type I collagen. Expression levels were normalized according to housekeeping gene ( $\beta$-actin). Significant differences between $\mathrm{Mg} / \mathrm{CSH}$ composite specimens and pure $\mathrm{CSH}$ were found $\left({ }^{*} p<\right.$ 0.05). The bars on the graphs are standard deviations. Mg: magnesium; CSH: calcium sulfate hemihydrate. 


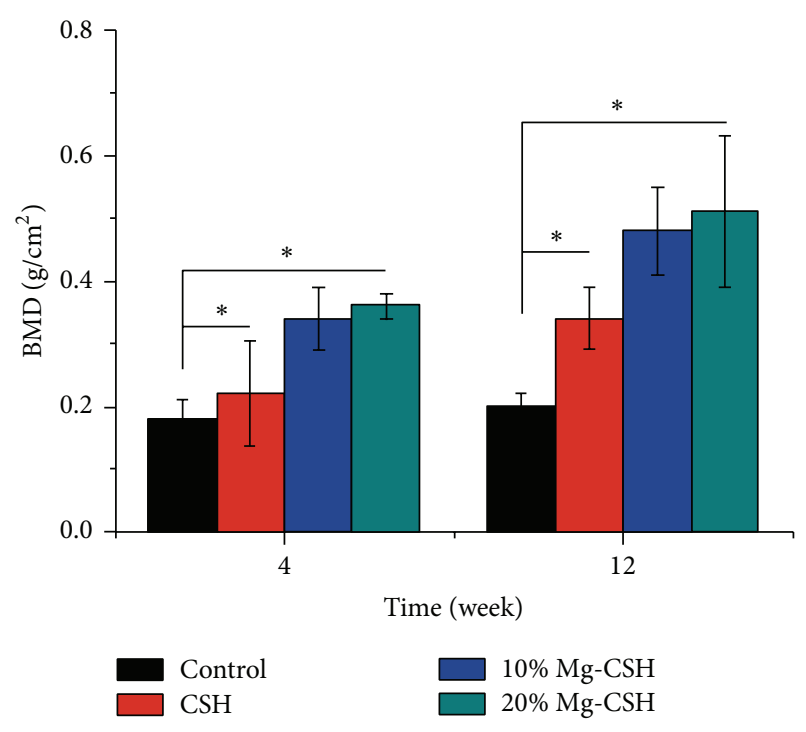

(a)

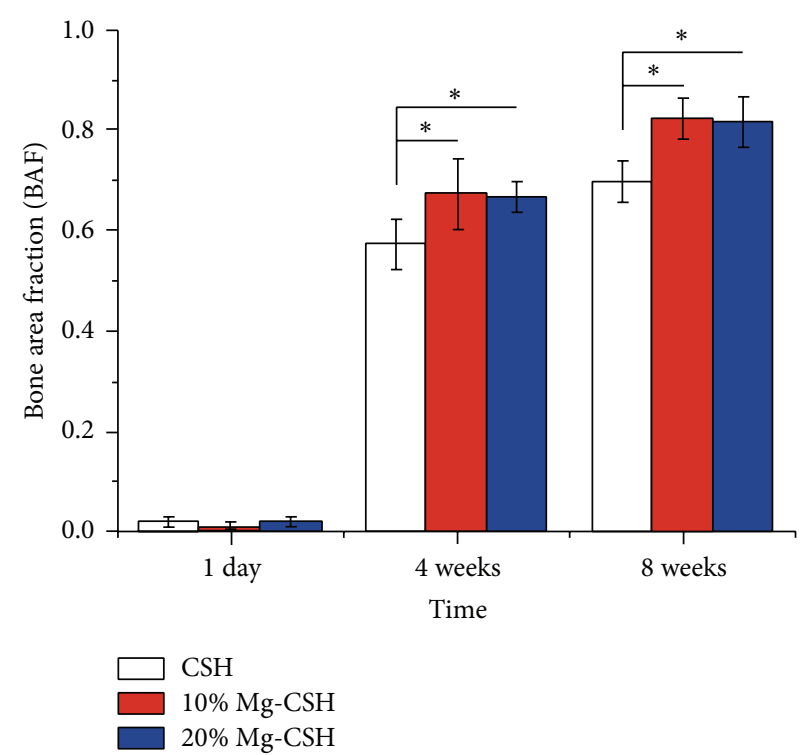

(b)

FIGURE 9: Quantitative analysis of BMD and BAF based on a dual energy X-ray absorptiometry system. (a) The local BMD after implantation for 4 and 12 weeks; (b) the BAF for 1 day, 4 weeks, and 12 weeks. * represents significant differences between $\mathrm{Mg} / \mathrm{CSH}$ composite specimens and pure $\mathrm{CSH}(p<0.05)$. The bars on the graphs are standard deviations. BMD: bone mineral density; BAF: new bone area fraction; Mg: magnesium; CSH: calcium sulfate hemihydrate.

materials exhibited no significant difference $(p>0.05)$ after implantation for 4 and 12 weeks, which was similar to BMP2 expression. Nevertheless, the expression levels of Coll I in both $\mathrm{Mg} / \mathrm{CSH}$ composite groups were significantly higher $(p<0.05)$ than that of CSH construct at 4 and 12 weeks (Figures 12(a) and 12(b)).

\section{Discussion}

Because bone is needed for mineral reserve, locomotion, load bearing, and protection of internal organs, bone defect causes disability and represents a medical and socioeconomic challenge. Tissue engineering is playing a critical role in bone regeneration [3]. An ideal bone grafting material should not only possess mechanical stability and excellent bioactivity, but also have osteoconductivity and osteoinductivity [2628]. In the present study, $\mathrm{Mg} / \mathrm{CSH}$ composite cement showed a prolonged setting time with improved injectability and enhanced mechanical strength due to the addition of $\mathrm{Mg}$ in comparison with CSH alone. In addition, a significantly improved degradability and promoting effect on the proliferation and osteogenic differentiation of cBMSCs in vitro were also exhibited by $\mathrm{Mg} / \mathrm{CSH}$ composite constructs. Histological evaluation and analyses of DXA and gene expression indicated that $\mathrm{Mg} / \mathrm{CSH}$ could enhance the efficiency of new bone formation in comparison with CSH. This implied that this novel injectable bone scaffold ( $\mathrm{Mg} / \mathrm{CSH}$ composite) would have a great potential for bone repair in tissue engineering.

The applicability of a bone cement biomaterial is largely dependent on its self-setting characteristics including injectability and setting time [29]. Additionally, in clinical applications, the cement must be extruded and applied before its initial setting start during operation [30]. In comparison with pure CSH paste, which had short initial and final setting time, $\mathrm{Mg} / \mathrm{CSH}$ composite pastes showed a relatively prolonged setting time. The prolonged setting time improved the injectability of cement and could result in an obvious advantage for surgeons by allowing more time to work before paste starts setting. Mechanical property of the hardened cement is another important index for the clinical applications of bone materials [29]. Nevertheless, previous studies have suggested that pure CSH cement fails to meet this index because of its poor and nearly constant mechanical strength $[9,31]$. In contrast, the compressive strength of $\mathrm{Mg} / \mathrm{CSH}$ composite constructs increased along with the increase of $\mathrm{Mg}$ content (in comparison with that of pure $\mathrm{CSH}$ ), and this would provide a much better mechanical support for the defect site during the bone regeneration process.

Bioactivity is defined as the ability of biomaterials to develop an adherent, direct, and strong bonding with the bone tissue [32]. Reportedly, CSH cement always lacks the capability of forming a chemical bond with bone tissue at the early stage of the implantation due to its poor bioactivity $[8$, 11-13]. However, in the present study, SEM and EDX analyses suggested that apatite deposition could not be observed on the surface of all the pure $\mathrm{CSH}$ and $\mathrm{Mg} / \mathrm{CSH}$ composite within 21 days after soaking in SBF. It was indicated that the addition of $\mathrm{Mg}$ might not contribute to the tendency of the CSH to form bone-like apatite in SBF. However, further studies are needed to improve the bioactivity of $\mathrm{Mg} / \mathrm{CSH}$ composite constructs. Moreover, the biomaterial should be degradable and gradually replaced by newly formed bone tissue [33]. The proper degradability of a biomaterial in a physiological environment is one of the most important 


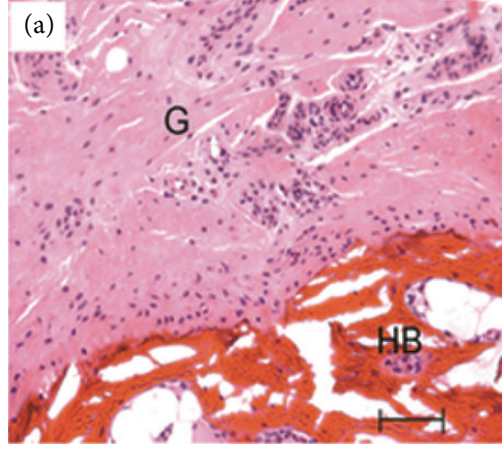

(a)

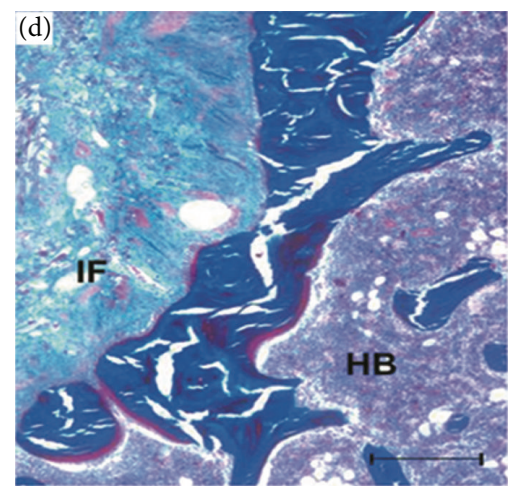

(d)

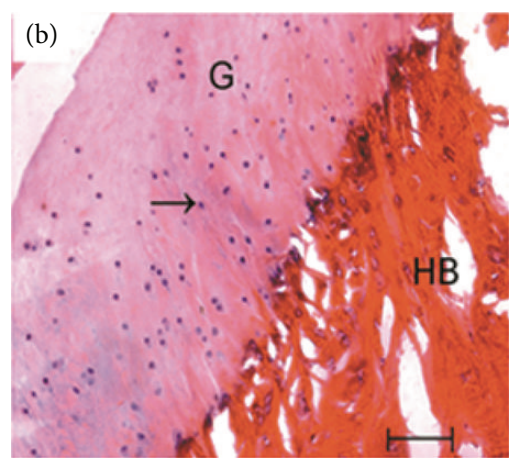

(b)

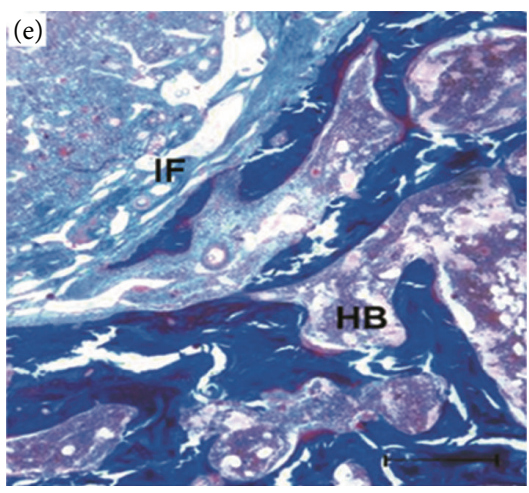

(e)

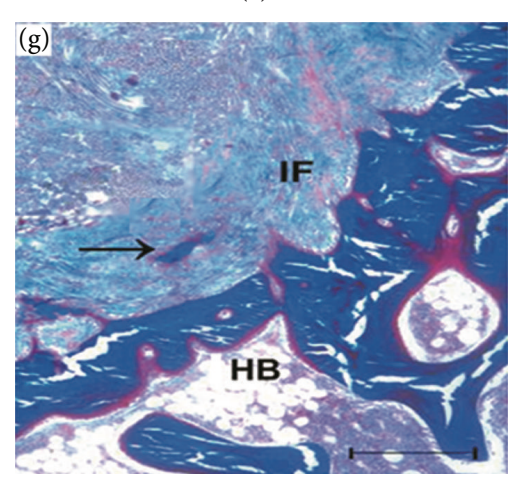

(g)

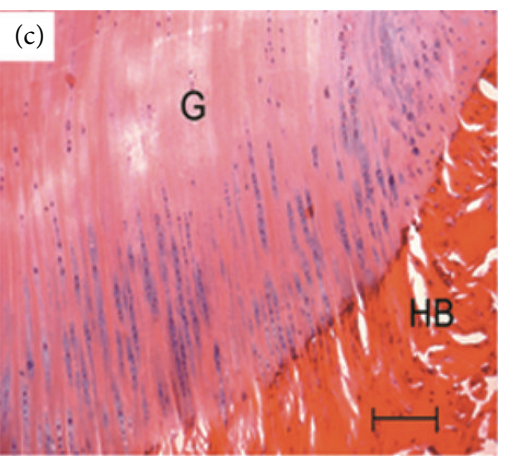

(c)

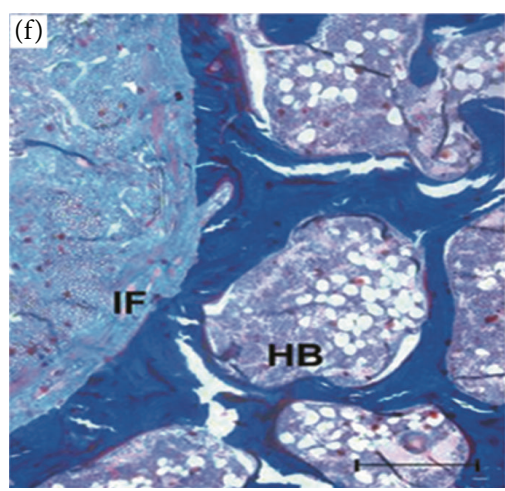

(f)

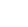




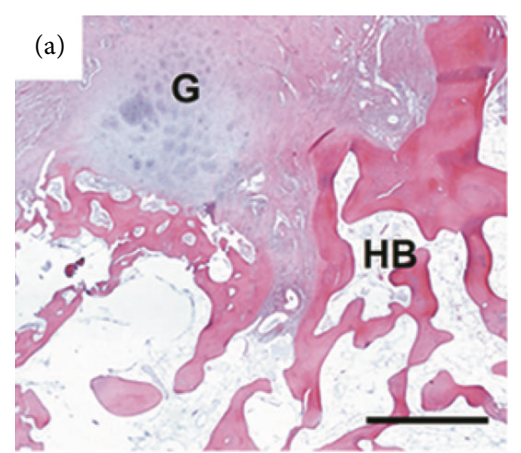

(a)

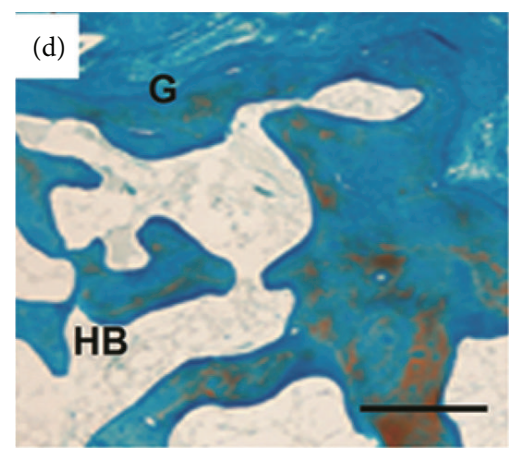

(d)

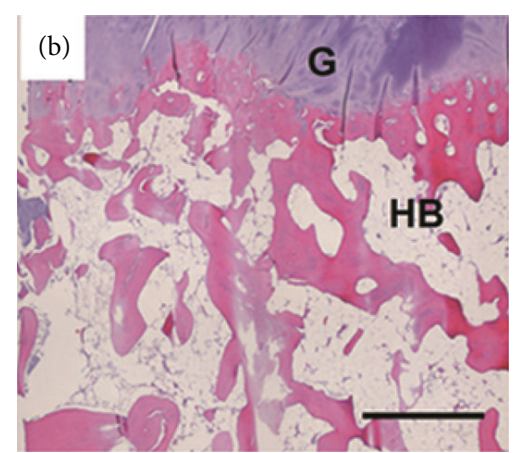

(b)

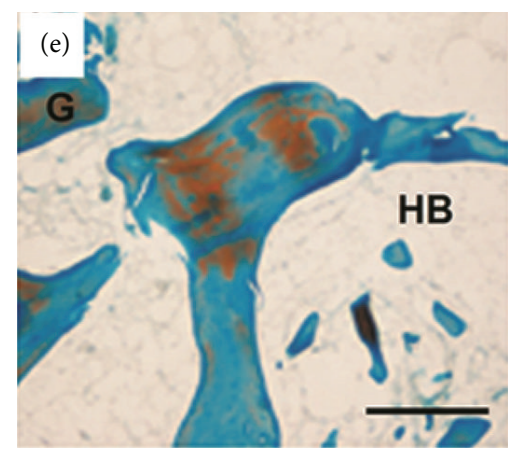

(e)

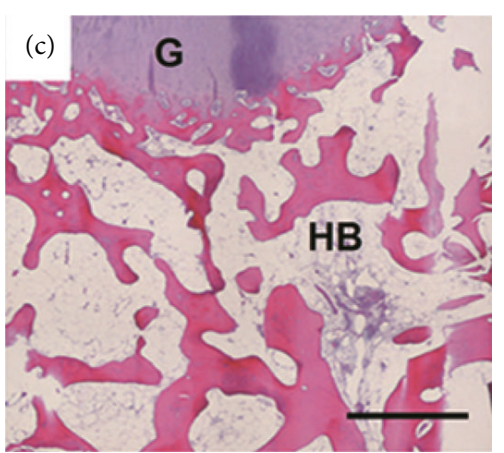

(c)

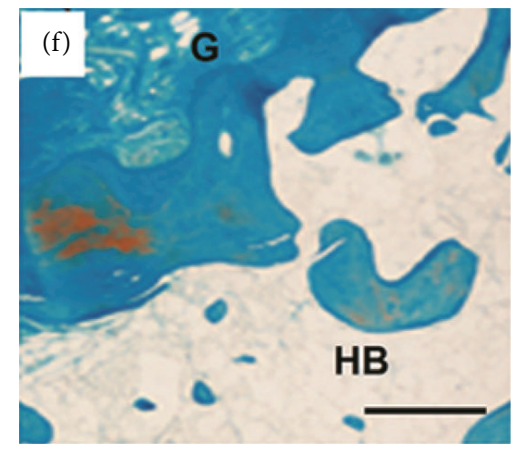

(f)

FIGURE 11: Histology photomicrographs of hematoxylin and eosin staining and Masson's Trichrome staining of the undecalcified bone defect sections after implantation. (a) Hematoxylin and eosin staining, $10 \% \mathrm{Mg} / \mathrm{CSH}$ for 4 weeks; (b) hematoxylin and eosin staining, $10 \% \mathrm{Mg} / \mathrm{CSH}$ for 8 weeks; (c) hematoxylin and eosin staining, 10\% Mg/CSH for 16 weeks; (d) Masson's Trichrome staining, 10\% Mg/CSH for 4 weeks; (e) Masson's Trichrome staining, 10\% Mg/CSH for 8 weeks; (f) Masson's Trichrome staining, 10\% Mg/CSH for 16 weeks. Scale bar: $200 \mu \mathrm{m}$. Abbreviations and signs used: graft $(\mathrm{G})$, host bone $(\mathrm{HB})$, magnesium $(\mathrm{Mg})$, and calcium sulfate hemihydrate $(\mathrm{CSH})$.

Furthermore, integrin plays an important role in the process of cell adhesion and extension and is an important protein connecting osteoblasts and bone substitutes, which is also a necessary specific gene in cell adhesion and osteogenesis [38]. In the present study, the enhanced expression of Coll I and integrin $\beta 1$ in cBMSCs cultured on $\mathrm{Mg} / \mathrm{CSH}$ composite constructs demonstrated the distinguished ability of cell adhesion and osteogenesis by adding $\mathrm{Mg}$, in comparison with pure $\mathrm{CSH}$. Therefore, the in vitro results indicated that this composite exhibited favorable biocompatibility by improving cell attachment and stimulating cell proliferation and differentiation.

Unlike autografts which have limited supply and significant potential risk of nerve damage, infecting, disease transmission, and immune response [28, 39], bone cement substitutes are promising approaches for bone regeneration [3]. Reportedly, $\mathrm{CSH}$ and $\mathrm{Mg}$ have been widely used in the clinic as a bone regeneration scaffold, while a variety of disadvantages remain. In the in vivo study, BMDs of $\mathrm{Mg} / \mathrm{CSH}$ graft were significantly higher than that of pure CSH at 4 and 12 weeks after implantation. Moreover, the increased BAF indicated that more new bone was formed in $\mathrm{Mg} / \mathrm{CSH}$ composite groups in comparison with CSH 4 and 8 weeks after graft. Histological evaluation also revealed that the new chondrocytes, trabeculae, and mature ossein appeared at the defect area, the boundaries between normal surrounding tissue and the composite were gradually indistinct due to biodegradation, and the residual materials were surrounded by areas of newly formed bone tissue during 8 weeks after implantation of composite cement. On the contrary, no new bone tissue was observed at the interface of CSH implant after 8 weeks, and the boundaries between normal surrounding tissue and CSH were distinct. It may be attributed to the addition of $\mathrm{Mg}$ which can accelerate the growth of new bone tissue as previously reported $[40,41]$. Therefore, these in vivo results demonstrated that $\mathrm{Mg} / \mathrm{CSH}$ composites exhibited not only faster biodegradability but also more effective osteogenesis and osteointegration at bone defect area than pure $\mathrm{CSH}$ cement.

\section{Conclusions}

A novel injectable $\mathrm{Mg} / \mathrm{CSH}$ composite was developed by incorporating $\mathrm{Mg}$ coated with fluoride into $\mathrm{CSH}$ in this study. $\mathrm{Mg} / \mathrm{CSH}$ composites showed a prolonged setting time with improved injectability. The mechanical strength and biodegradability of the $\mathrm{Mg} / \mathrm{CSH}$ composite were improved. The $\mathrm{Mg} / \mathrm{CSH}$ composite could promote the attachment, proliferation, and differentiation of canine cBMSCs and exhibit excellent biocompatibility without cytotoxicity. Additionally, the $\mathrm{Mg} / \mathrm{CSH}$ composite implant also showed effective osteogenesis and osteointegration. In conclusion, this new kind of 


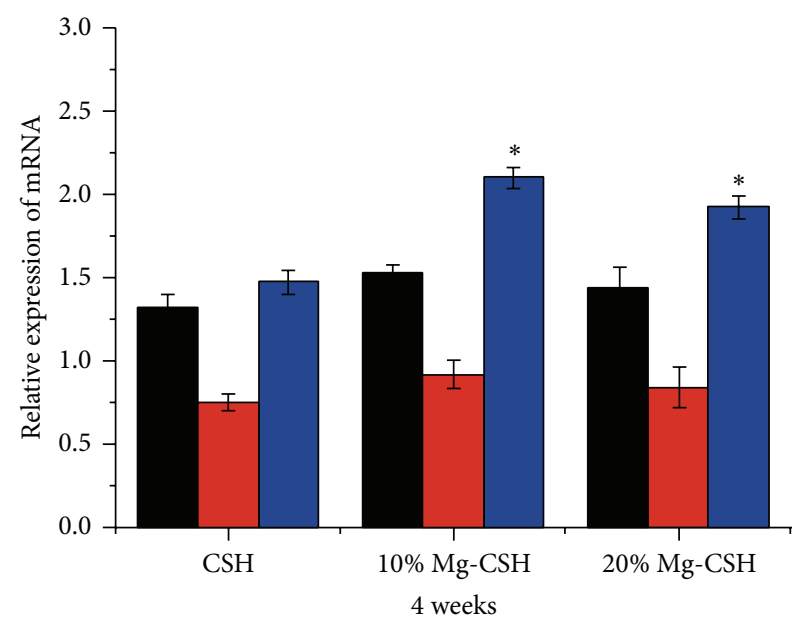

(a)

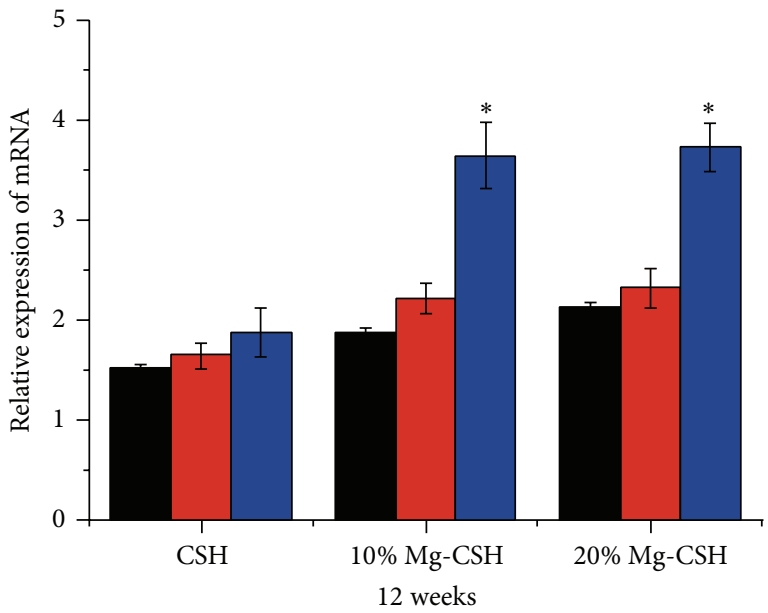

Osteopontin BMP-2 Type I collagen

FIGURE 12: mRNA relative expressions of osteopontin, BMP-2, and type I collagen after implantation. (a) After implantation for 4; (b) after implantation for 12 weeks. Expression levels are normalized according to housekeeping gene ( $\beta$-actin). * stands for significant differences of type I collagen relative expressions between $\mathrm{Mg} / \mathrm{CSH}$ composite specimens and pure CSH $(p<0.05)$. The bars on the graphs are standard deviations. Mg: magnesium; CSH: calcium sulfate hemihydrate; BMP-2: bone morphogenetic protein- 2 .

injectable biomaterial with improved properties would develop a more promising tissue graft substitute for bone regeneration.

\section{Conflict of Interests}

The authors declare that there is no conflict of interests regarding the publication of this paper.

\section{Acknowledgments}

This research was supported by State Natural Science Fund, China (Grant no. 81200819), and Special Financial Grant (Grant no. 2013T60943) and the Second Class General Financial Grant (Grant no. 2012M512121) from China Postdoctoral Science Foundation.

\section{References}

[1] A. Nauth, M. D. McKee, T. A. Einhorn, J. T. Watson, R. Li, and E. H. Schemitsch, "Managing bone defects," Journal of Orthopaedic Trauma, vol. 25, no. 8, pp. 462-466, 2011.

[2] R. J. O'Keefe and J. Mao, "Bone tissue engineering and regeneration: From discovery to the clinic-an overview," Tissue Engineering-Part B: Reviews, vol. 17, no. 6, pp. 389-392, 2011.

[3] U. Kneser, D. J. Schaefer, E. Polykandriotis, and R. E. Horch, "Tissue engineering of bone: the reconstructive surgeon's point of view," Journal of Cellular and Molecular Medicine, vol. 10, no. 1, pp. 7-19, 2006.

[4] S. Gitelis, P. Piasecki, T. Turner, W. Haggard, J. Charters, and R. Urban, "Use of a calcium sulfate-based bone graft substitute for benign bone lesions," Orthopedics, vol. 24, no. 2, pp. 162-166, 2001.

[5] D. J. Hak, "The use of osteoconductive bone graft substitutes in orthopaedic trauma," Journal of the American Academy of Orthopaedic Surgeons, vol. 15, no. 9, pp. 525-536, 2007.

[6] A. S. Coetzee, "Regeneration of bone in the presence of calcium sulfate," Archives of Otolaryngology, vol. 106, no. 7, pp. 405-409, 1980.

[7] Á. Lazáry, B. Balla, J. P. Kósa et al., "Effect of gypsum on proliferation and differentiation of MC3T3-E1 mouse osteoblastic cells," Biomaterials, vol. 28, no. 3, pp. 393-399, 2007.

[8] D. Stubbs, M. Deakin, P. Chapman-Sheath et al., "In vivo evaluation of resorbable bone graft substitutes in a rabbit tibial defect model," Biomaterials, vol. 25, no. 20, pp. 5037-5044, 2004.

[9] W. S. Pietrzak and R. Ronk, "Calcium sulfate bone void filler: a review and a look ahead," Journal of Craniofacial Surgery, vol. 11, no. 4, pp. 327-333, 2000.

[10] J.van der Stok, E. M. M. van Lieshout, Y. El-Massoudi, G. H. van Kralingen, and P. Patka, "Bone substitutes in the Netherlandsa systematic literature review," Acta Biomaterialia, vol. 7, no. 2, pp. 739-750, 2011.

[11] M. V. Cabañas, L. M. Rodríguez-Lorenzo, and M. Vallet-Regí, "Setting behavior and in vitro bioactivity of hydroxyapatite/ calcium sulfate cements," Chemistry of Materials, vol. 14, no. 8, pp. 3550-3555, 2002.

[12] G. Orsini, J. Ricci, A. Scarano et al., "Bone-defect healing with calcium-sulfate particles and cement: an experimental study in rabbit," Journal of Biomedical Materials Research Part B: Applied Biomaterials, vol. 68, no. 2, pp. 199-208, 2004.

[13] A. Jamali, A. Hilpert, J. Debes, P. Afshar, S. Rahban, and R. Holmes, "Hydroxyapatite/calcium carbonate (HA/CC) vs. plaster of Paris: a histomorphometric and radiographic study in 
a rabbit tibial defect model," Calcified Tissue International, vol. 71, no. 2, pp. 172-178, 2002.

[14] F. Witte, V. Kaese, H. Haferkamp et al., "In vivo corrosion of four magnesium alloys and the associated bone response," Biomaterials, vol. 26, no. 17, pp. 3557-3563, 2005.

[15] M. P. Staiger, A. M. Pietak, J. Huadmai, and G. Dias, "Magnesium and its alloys as orthopedic biomaterials: a review," Biomaterials, vol. 27, no. 9, pp. 1728-1734, 2006.

[16] F. Witte, J. Fischer, J. Nellesen et al., "In vitro and in vivo corrosion measurements of magnesium alloys," Biomaterials, vol. 27, no. 7, pp. 1013-1018, 2006.

[17] E. Zhang, L. Xu, and K. Yang, "Formation by ion plating of Ti-coating on pure $\mathrm{Mg}$ for biomedical applications," Scripta Materialia, vol. 53, no. 5, pp. 523-527, 2005.

[18] L. Li, J. Gao, and Y. Wang, "Evaluation of cyto-toxicity and corrosion behavior of alkali-heat-treated magnesium in simulated body fluid," Surface and Coatings Technology, vol. 185, no. 1, pp. 92-98, 2004.

[19] G. Song, "Control of biodegradation of biocompatable magnesium alloys," Corrosion Science, vol. 49, no. 4, pp. 1696-1701, 2007.

[20] K. Y. Chiu, M. H. Wong, F. T. Cheng, and H. C. Man, "Characterization and corrosion studies of fluoride conversion coating on degradable Mg implants," Surface and Coatings Technology, vol. 202, no. 3, pp. 590-598, 2007.

[21] C. Liu, Y. Xin, X. Tian, and P. K. Chu, "Corrosion behavior of AZ91 magnesium alloy treated by plasma immersion ion implantation and deposition in artificial physiological fluids," Thin Solid Films, vol. 516, no. 2-4, pp. 422-427, 2007.

[22] L. Zhao, M. D. Weir, and H. H. K. Xu, "An injectable calcium phosphate-alginate hydrogel-umbilical cord mesenchymal stem cell paste for bone tissue engineering," Biomaterials, vol. 31, no. 25, pp. 6502-6510, 2010.

[23] T. Kokubo, "Surface chemistry of bioactive glass-ceramics," Journal of Non-Crystalline Solids, vol. 120, no. 1-3, pp. 138-151, 1990.

[24] Z. Guo, J. Yang, X. Liu et al., "Biological features of mesenchymal stem cells from human bone marrow," Chinese Medical Journal (England), vol. 114, no. 9, pp. 950-953, 2001.

[25] K. J. Livak and T. D. Schmittgen, "Analysis of relative gene expression data using real-time quantitative PCR and the $2^{-\Delta \Delta C T}$ method," Methods, vol. 25, no. 4, pp. 402-408, 2001.

[26] G. F. Muschler, C. Nakamoto, and L. G. Griffith, "Engineering principles of clinical cell-based tissue engineering," The Journal of Bone and Joint Surgery-American Volume, vol. 86, no. 7, pp. 1541-1558, 2004.

[27] X. Liu and P. X. Ma, "Polymeric scaffolds for bone tissue engineering," Annals of Biomedical Engineering, vol. 32, no. 3, pp. 477-486, 2004.

[28] J. Liu, K. Mao, Z. Liu et al., "Injectable biocomposites for bone healing in rabbit femoral condyle defects," PLOS ONE, vol. 8, no. 10, Article ID e75668, 2013.

[29] Z. Chen, H. Liu, X. Liu, and F.-Z. Cui, "Injectable calcium sulfate/mineralized collagen-based bone repair materials with regulable self-setting properties," Journal of Biomedical Materials Research Part A, vol. 99, no. 4, pp. 554-563, 2011.

[30] X. Liu, X. M. Wang, Z. Chen et al., "Injectable bone cement based on mineralized collagen," Journal of Biomedical Materials Research Part B: Applied Biomaterials, vol. 94, no. 1, pp. 72-79, 2010.
[31] S. M. Kenny and M. Buggy, "Bone cements and fillers: a review," Journal of Materials Science: Materials in Medicine, vol. 14, no. 11, pp. 923-938, 2003.

[32] G. Hannink and J. J. C. Arts, "Bioresorbability, porosity and mechanical strength of bone substitutes: what is optimal for bone regeneration?" Injury, vol. 42, no. 2, pp. S22-S25, 2011.

[33] G. Hu, L. Xiao, H. Fu, D. Bi, H. Ma, and P. Tong, "Study on injectable and degradable cement of calcium sulphate and calcium phosphate for bone repair," Journal of Materials Science: Materials in Medicine, vol. 21, no. 2, pp. 627-634, 2010.

[34] C. Wu, Y. Ramaswamy, Y. Zhu et al., "The effect of mesoporous bioactive glass on the physiochemical, biological and drugrelease properties of poly(dl-lactide-co-glycolide) films," Biomaterials, vol. 30, no. 12, pp. 2199-2208, 2009.

[35] E. Kon, A. Muraglia, A. Corsi et al., "Autologous bone marrow stromal cells loaded onto porous hydroxyapatite ceramic accelerate bone repair in critical-size defects of sheep long bones," Journal of Biomedical Materials Research, vol. 49, no. 3, pp. 328337, 2000.

[36] C. Maniatopoulos, J. Sodek, and A. H. Melcher, "Bone formation in vitro by stromal cells obtained from bone marrow of young adult rats," Cell and Tissue Research, vol. 254, no. 2, pp. 317-330, 1988.

[37] G. Yajia, X. Qin, W. Bin et al., "Evaluation of breast cancer extension with diffusion-weighted MR imaging," Chinese Journal of Radiology, vol. 41, pp. 959-964, 2007.

[38] H.-Y. Liu, X. Liu, L.-P. Zhang, H.-J. Ai, and F.-Z. Cui, "Improvement on the performance of bone regeneration of calcium sulfate hemihydrate by adding mineralized collagen," Tissue Engineering Part A, vol. 16, no. 6, pp. 2075-2084, 2010.

[39] M. Bohner, "Resorbable biomaterials as bone graft substitutes," Materials Today, vol. 13, no. 1-2, pp. 24-30, 2010.

[40] A. Pietak, P. Mahoney, G. J. Dias, and M. P. Staiger, "Bonelike matrix formation on magnesium and magnesium alloys," Journal of Materials Science: Materials in Medicine, vol. 19, no. 1, pp. 407-415, 2008.

[41] Y. W. Song, D. Y. Shan, and E. H. Han, "Electrodeposition of hydroxyapatite coating on AZ91D magnesium alloy for biomaterial application," Materials Letters, vol. 62, no. 17-18, pp. 3276-3279, 2008. 

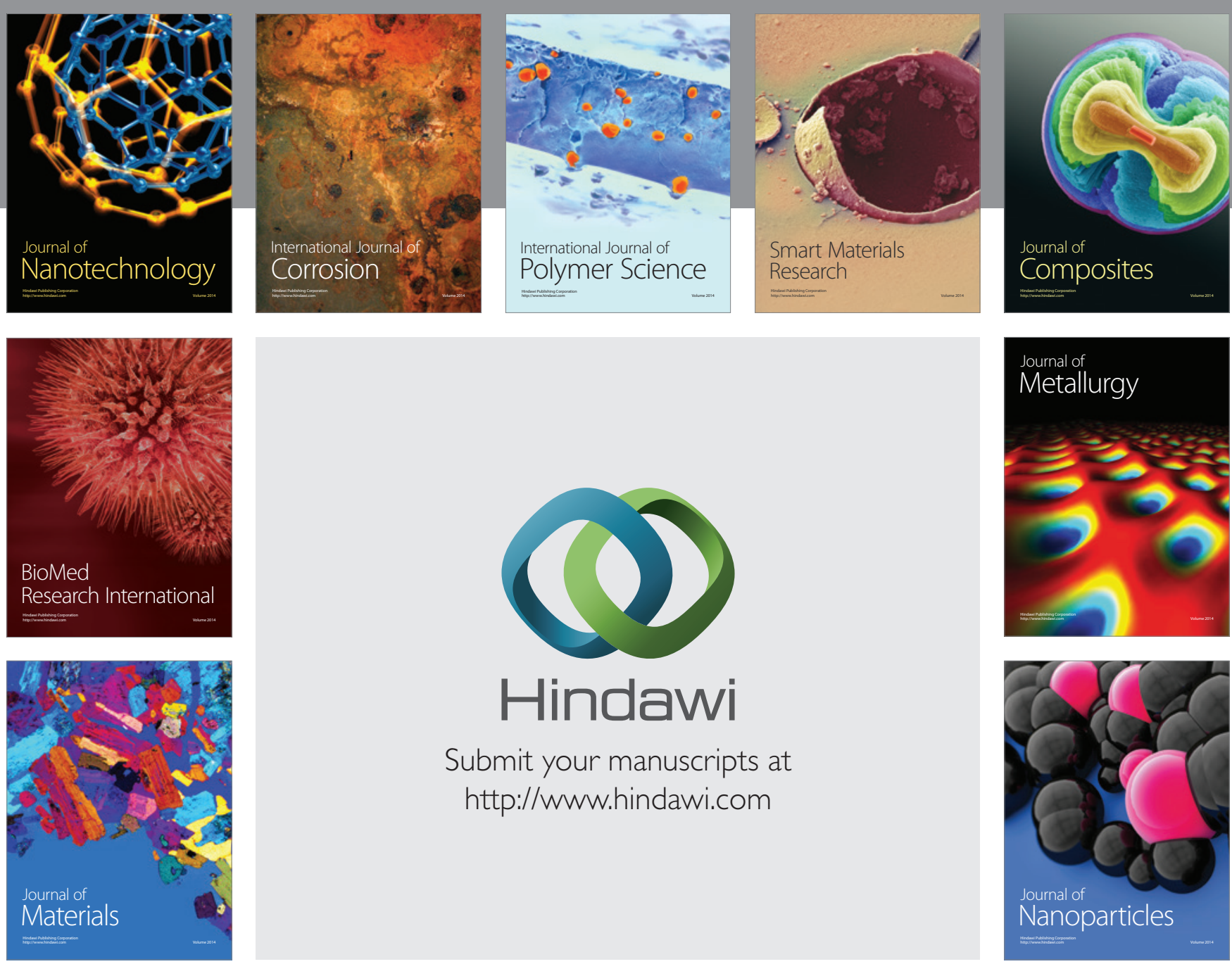

Submit your manuscripts at http://www.hindawi.com
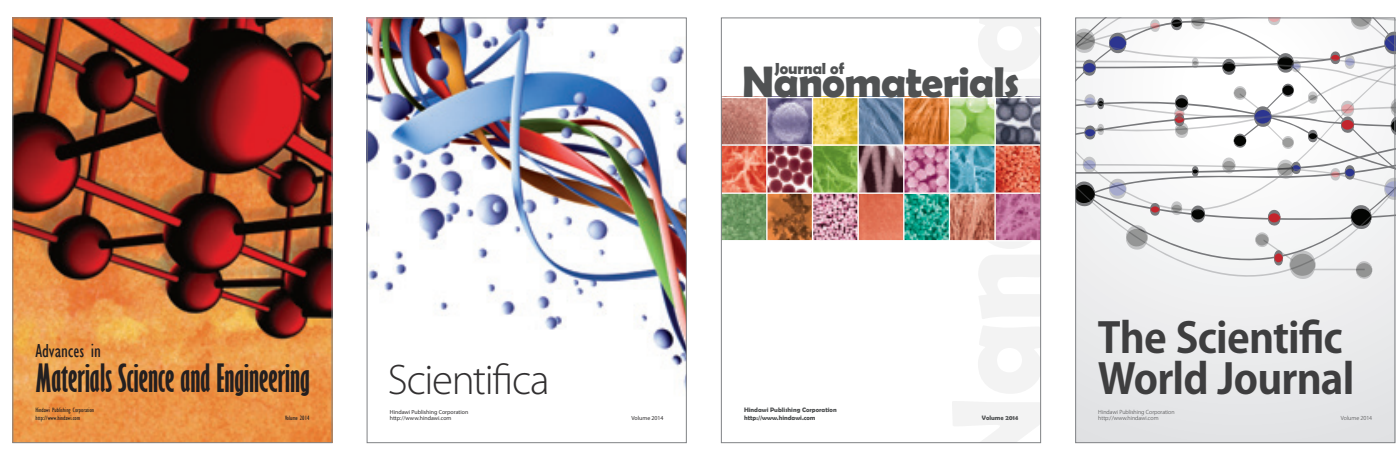

\section{The Scientific World Journal}
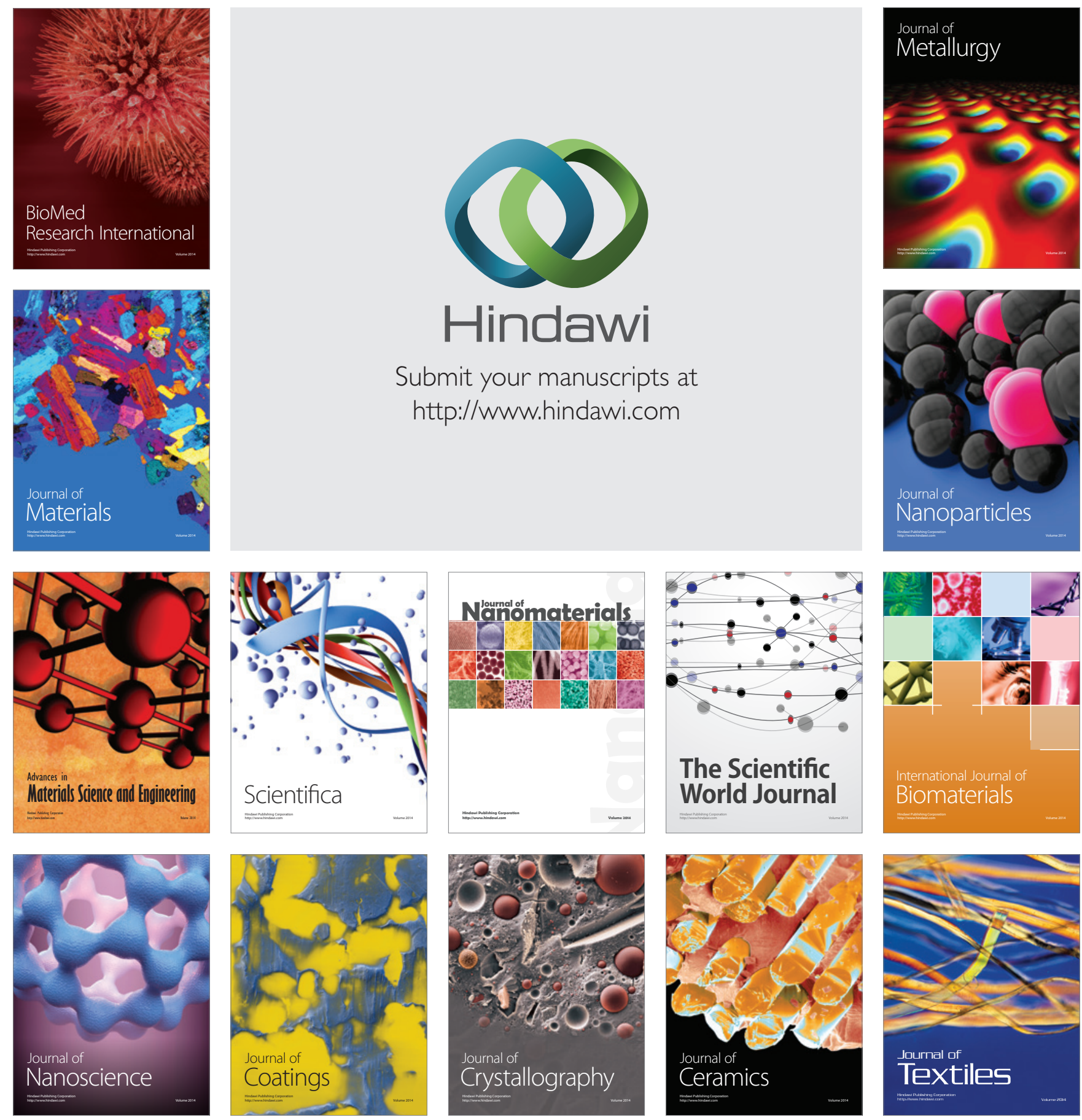